\title{
Characterization of dust emission from alluvial sources using aircraft observations and high-resolution modeling
}

\author{
K. Schepanski, ${ }^{1,2}$ C. Flamant, ${ }^{3}$ J.-P. Chaboureau, ${ }^{4}$ C. Kocha,,${ }^{3,5}$ J. R. Banks, ${ }^{6}$ \\ H. E. Brindley, ${ }^{6}$ C. Lavaysse, ${ }^{3}$ F. Marnas, ${ }^{7}$ J. Pelon, ${ }^{3}$ and P. Tulet ${ }^{8}$ \\ Received 5 December 2012; revised 21 May 2013; accepted 25 May 2013; published 8 July 2013.
}

[1] We investigate mineral dust emission from alluvial sediments within the upland region in northern Mauritania in the vicinity of a decaying nocturnal low-level jet (LLJ). For the first time, the impact of valleys that are embedded in a rather homogeneous surrounding is investigated with regard to their role as dust source. Measures for local atmospheric dust burden were retrieved from airborne observations, satellite observations, and model simulations and analyzed in order to provide complementary information at different horizontal scales. Observations by the LEANDRE Nouvelle Generation backscatter lidar system flying aboard the French Falcon 20 aircraft were taken along five parallel flight legs perpendicular to the orientation of the main valley system dominating the topography of the study area. Results from a comparison of lidar-derived extinction coefficients with topography and aerial photographs confirm the relevance of (1) alluvial sediments at the valley bottoms as a dust source, and (2) the break-down of the nocturnal LLJ as a trigger for dust emission in this region. An evaluation of the AROME regional model, forecasting dust at high resolution (5 km grid), points toward an under-representation of alluvial dust sources in this region. This is also evident from simulations by the MesoNH research model. Although MesoNH simulations show higher dust loadings than AROME, which are more comparable to the observations, both models underestimate the dust concentrations within the boundary layer compared to lidar observations. A sensitivity study on the impact of horizontal grid spacing $(5 \mathrm{~km}$ versus $1 \mathrm{~km}$ ) highlights the importance of spatial resolution on simulated dust loadings.

Citation: Schepanski, K., C. Flamant, J.-P. Chaboureau, C. Kocha, J. R. Banks, H. E. Brindley, C. Lavaysse, F. Marnas, J. Pelon, and P. Tulet (2013), Characterization of dust emission from alluvial sources using aircraft observations and high-resolution modeling, J. Geophys. Res. Atmos., 118, 7237-7259, doi:10.1002/jgrd.50538.

\section{Introduction}

[2] Mineral dust plays an important role in the global weather and climate system. Airborne dust interacts directly

\footnotetext{
${ }^{1}$ School of Earth and Environment, University of Leeds, Leeds, UK.

${ }^{2}$ Now at Leibniz Institute for Tropospheric Research, Leipzig, Germany.

${ }^{3}$ Laboratoire Atmosphères, Milieux, Observations Spatiales, CNRSUniversité Pierre et Marie Curie and Université Versailles Saint Quentin, Paris, France.

${ }^{4}$ Laboratoire d'Aérologie, University of Toulouse and CNRS, Toulouse, France.

${ }^{5}$ Centre National de Recherches Météorologique, CNRM and GAME, URA 1357, CNRS and Météo France, Toulouse, France.

${ }^{6}$ Space and Atmospherics Physics Group, Imperial College London, London, UK

${ }^{7}$ Laboratoire des Sciences du Climat et de l'Environnement, CEA and CNRS, Gif-sur-Yvette, France.

${ }^{8}$ Laboratoire de l'Atmosphère et des Cyclones, UMR 8105, Université de La Réunion, CNRS and Météo-France, Saint-Denis de La Réunion, France.

Corresponding author: K. Schepanski, Leibniz Institute for Tropospheric Research, Permoser Str. 15, DE-04318 Leipzig, Germany. (schepanski@tropos.de)

(C)2013. American Geophysical Union. All Rights Reserved. 2169-897X/13/10.1002/jgrd.50538
}

and indirectly with the Earth's radiation budget [Foster et al., 2007]. Furthermore, dust aerosols act as condensation nuclei for cloud particles and thus may have impacts on cloud formation processes and alter cloud properties [e.g., Hoose et al., 2008; Lohmann, 2002; Bangert et al., 2012] as well as precipitation rates [e.g., DeMott et al., 2003; Rosenfeld et al., 2001; Wurzler et al., 2000]. Mineral dust also acts as a transport medium for micro-nutrients and therefore as a fertilizer for marine and terrestrial ecosystems [e.g., Fung et al., 2000; Jickells et al., 2005; Mahowald et al., 2005; Sarthou et al., 2003]. A detailed knowledge on the location of dust sources, the dust emission process itself, and atmospheric and surface properties affecting dust emission are a necessary prerequisite for an as accurate as possible estimate of dust impacts on our environment. Although progress has been made in understanding dust emission in space and time, the reasons for interannual variability of dust source activations remain unclear. Recent studies on dust source locations using satellite data show a remarkable interannual variability in the frequency of dust source activation events [Schepanski et al., 2012a; Tegen et al., 2013]. An important fraction of identified dust sources that are frequently active are located within the foothills of mountains 
[Prospero et al., 2002; Schepanski et al., 2009; Ginoux et al., 2012]. The geomorphology of these sources shows a high fraction of alluvial sediment. Intensive rainfall over a short time period leads to high surface runoff, which accumulates on lower terrain, potentially causing flash flooding. Debris and surface sediments eroded by runoff water are transported downhill and are finally deposited in these valley bottoms where the water flow slows down. As the size fraction of transported sediment and debris gets segregated depending on the flow velocity, particle size, and density, the size fraction of deposited sediments becomes smaller the flatter and wider the valley bottom becomes [Shao, 2008]. These alluvial sediments are very prone to wind erosion [e.g., Reheis and Kihl, 1995; Gillette et al., 1980]. A long-term field measurement study by Reheis and Kihl [1995] suggests an increase in dust emission flux after intensive rainfall periods. The supply of fine sediments suitable for dust emission is enlarged due to freshly deposited layers of alluvial sediments. A recent study by Schepanski et al. [2012b] analyzing space-borne radar data shows a relation between intensive rainfall events and soil surface changes that are related to freshly deposited layers of alluvial sediments. The authors identify changes in surface sediments through loss of coherence in radar interferograms after intense rainfall periods that often cause flash floods. The role of alluvial sediments serving as dust sources suggests an important link between the atmospheric water cycle and the dust cycle that requires further investigation. The impact of the atmospheric water cycle on the dust cycle may help to explain interannual variability in local dust emission fluxes from alluvial sources.

[3] Dust uplift is mainly controlled by two factors, soil condition and surface wind speed [e.g., Bagnold, 1941; Marticorena and Bergametti, 1995; Shao et al., 2011]. Local wind speed distributions may change over the course of the year due to seasonally changing weather, but also changing soil properties can control the emissivity of a dust source [Bullard et al., 2011]. The emission efficiency of a dust source is, among other factors such as vegetation cover and soil moisture, controlled by surface type and particle size distribution [e.g., Gillette et al., 1980; Marticorena and Bergametti, 1995; Tegen et al., 2002]. Kok [2011] showed that the simulation of dust emission fluxes from clay surfaces can be improved by describing clay aggregates as brittle material.

[4] Dust emission, deposition, and atmospheric dust loadings have been studied in various ways using in situ measurements [e.g., Formenti et al., 2011; Niedermeier et al., 2012], remote-sensing observations and numerical modeling at the multiscale. Ground-based measurements are very useful for long-term observation and monitoring, whereas airborne measurements allow for the design of experiments that can be adapted in time and space, depending on the aim of the study. Utilizing the possibility to access remote dust source areas, the evolution of a fresh dust plume can be explored in detail. Spaceborne instruments are generally designed to last for a significant length of time and, dependent on the orbit of their satellite platform, can provide regional or global coverage. Hence they can place the more localized observations available from the ground or aircraft in a wider temporal and spatial context.
[5] In this study we aim to characterize dust emission from sources located within complex terrain initiated by a morning breakdown of a nocturnal low-level jet (LLJ) over north Mauritania during the RAIN4DUST aircraft experiment in June 2011. The study takes advantage of a synergistic analysis of airborne measurements and mesoscale modeling experiments. The airborne measurements acquired over a $100 \mathrm{~km} \times 100 \mathrm{~km}$ test bed provide detailed insight into dust emission from sources within complex terrain, whereas the numerical model simulations are used to incorporate the observations into a general understanding. Section 2 provides an overview on the RAIN4DUST project and the airborne measurement campaign in June 2011. Section 3 gives an overview on instruments and models used within this study. Section 4 presents a case study characterizing a dust emission event from sources within complex terrain. Section 5 compares the field observations to model simulations from AROME and Meso-NH. A discussion follows in section 6 , and conclusions are drawn in section 7 .

\section{The RAIN4DUST Project}

[6] The RAIN4DUST project investigates the contribution of flash floods to the variability of dust emission in the Sahara. The project considers both the role of sediment supply and atmospheric conditions, i.e., the breakdown of the nocturnal LLJ for dust uplift, and their interannual variability. It is structured in two parts: (1) the observation of the dust emission process from alluvial sources within complex terrain over North Africa, and (2) the contribution of intensive rainfall periods to sediment supply and ultimately the interannual variability of dust emission. The present manuscript focuses on the first part. Results on the second part are described in Schepanski et al. [2012b].

[7] Over arid and semiarid areas occasionally, heavy rainfall events erode the barren surface and lead to fresh layers of alluvial sediments accumulating at the bottom floor of drainage systems and desert valleys. Although recent studies analyzing satellite dust products highlight the importance of dust source located in complex terrain [e.g., Schepanski et al., 2007, 2009, 2012a], to the best of our knowledge, no airborne observations have yet been made of the emission process from sources within complex terrain.

[8] The observational part of the RAIN4DUST project is an aircraft campaign funded by the European Facility for Airborne Research (EUFAR) as part of the European Council with 10 flight hours (three flights) aboard the Falcon 20 (F20) operated by SAFIRE (Service des Avions Français Instrumentés pour la Recherche en Environment). The research flights were integrated into the Fennec aircraft campaign that took place over the Saharan heat low region in June 2011. One of the aims of the Fennec project is the characterization of the Saharan atmospheric boundary layer dynamics and related processes.

[9] The F20 aircraft was based at Fuerteventura (Canary Islands, Spain) from 1-23 June 2011. During this period data were obtained from three flights, of about $3.5 \mathrm{~h}$ duration, in order to characterize the onset of dust emission from sources located within complex terrain (Figure 1). The mountain regions over north Mauritania was chosen as the research domain as it is an identified dust source region that shows 
a)

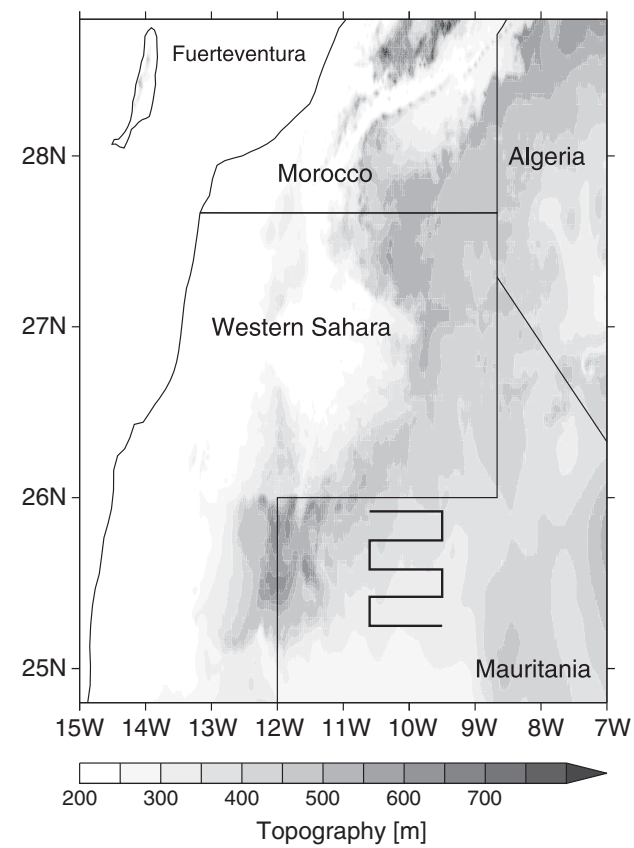

b)

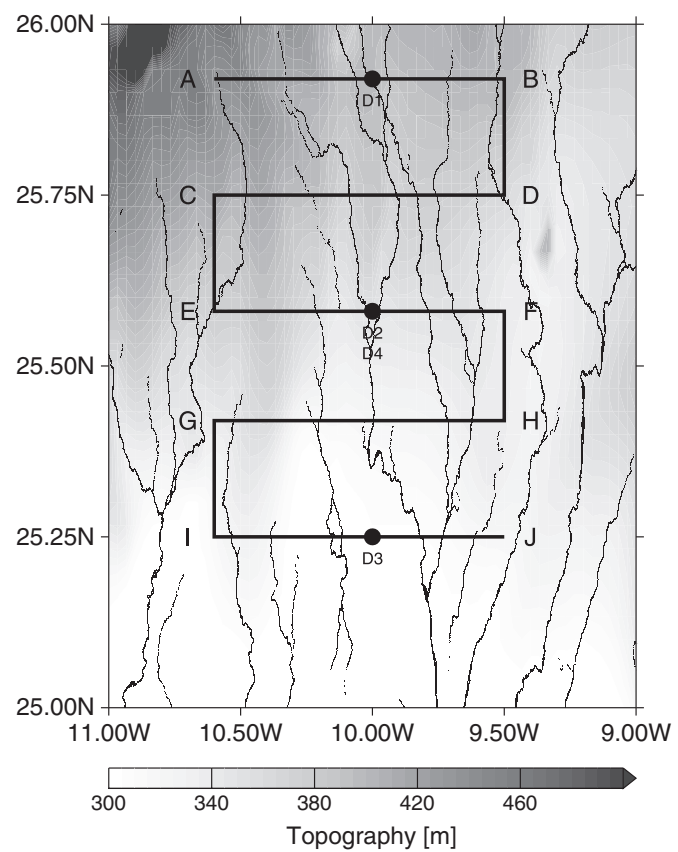

Figure 1. (a) Overview of the research area and schematic on the flight track (solid black line) and topography (gray shades). (b) Detailed view on the research domain. Schematic of the flight track is given by solid black line. Dropsondes, named D1, D2, D3, and D4 were released at $10^{\circ} \mathrm{W}$ along the flight track as indicated by filled circles. Topography is given in gray shades, and location of drainage systems is indicated in black.

frequent dust emission during the morning hours in June [Schepanski et al., 2009].

[10] Schepanski et al. [2009] suggest that local dust emission during the morning hours is caused by the break-down of the nocturnal low-level jet (LLJ), triggered by the development of the day-time convective boundary layer and the related downward transport of momentum to the surface leading to a sudden increase in the surface wind speed. To achieve the objectives of RAIN4DUST, the observations are focused on the decaying nocturnal LLJ and the consequent onset of dust emission. To observe the break-down of nocturnal LLJ and the subsequent onset of dust emission, aircraft take-offs were scheduled so as to allow the aircraft to reach the research domain over northern Mauritania at around 09:45 UTC, which corresponds to local time.

[11] The research area itself is located in an arid environment with sparse vegetation and is characterized by several desert valleys and drainage systems (Figure 1b). To explore the onset of dust emission in the vicinity of the break-down of the nocturnal LLJ, a desert valley system orientated in meridional direction along $10^{\circ} \mathrm{W}$ was chosen as a test bed. The orientation of the valley also represents the expected main wind direction related to dust emission during June. The northern part of the research area is characterized by higher elevated terrain (above $400 \mathrm{~m}$ above mean sea level (amsl) compared to around 300 to $320 \mathrm{~m}$ amsl) and steeper valleys, especially over the northwestern part. Generally, the complexity of the terrain is higher in the western part of the domain than over the eastern part.

[12] Northerly winds are often associated with a zone of high pressure, also referred to as the "Azores high," to the west of the African continent. They act to ventilate the region south of the Atlas mountains by advecting maritime air masses into the region. Due to the stabilizing effect of the inflowing maritime air, the development of a nocturnal LLJ is likely. The break-down of the nocturnal LLJ due to the growing convective boundary layer leads to increased surface wind speeds during the morning and thus frequently to dust emission, if the wind speeds are high enough.

[13] To capture both the temporal evolution and spatial distribution of dust emission, each flight comprised five zonal legs running perpendicular to the orientation of the main valleys and the expected wind direction (Figure 1 and Table 1). Each leg was about $120 \mathrm{~km}$ long and was centered at $10^{\circ} \mathrm{W}$. Each leg was designed to transect regions between $10.5^{\circ} \mathrm{W}$ and $9.5^{\circ} \mathrm{W}$. By shifting to a parallel leg downwinds, the evolution of a dust plume could thus be examined.

[14] Rainfall estimates from the Tropical Rainfall Measuring Mission (TRMM) 3B42 product [Huffman et al., 2007] show a period of intense rainfall during 6-8 May 2011 with a total rainfall of about $84 \mathrm{~mm} \mathrm{day}^{-1}$ averaged over the research area. Considering the catchment area related to the area covered by the flight legs $\left(25.0^{\circ}-27.0^{\circ} \mathrm{N}, 11.0^{\circ}-\right.$ $\left.9.0^{\circ} \mathrm{W}\right)$ the rain fell over an area of $44,450 \mathrm{~km}^{2}$ with a maximum averaged rainfall rate of $35 \mathrm{~mm} \mathrm{day}^{-1}$ on 9 May 2011. No significant vegetation cover is evident from the aerial photographs taken during the flights. Following Schepanski et al. [2012b], the intense rainfall and associated flash flooding was sufficient to cause changes in the surface related to the deposition of a fresh layer of alluvial sediment, which we would expect to act as a strong dust source. We therefore expect an increased sensitivity for wind erosion during 
Table 1. Details on Legs of F20 Flight fs110013 on 11 June 2011: Geographical Position of Start/End of Each Leg as Well as Start/End Time of Each Leg

\begin{tabular}{lccccc}
\hline & \multicolumn{2}{c}{ Geographic Position } & & \multicolumn{2}{c}{ Time (UTC) } \\
\cline { 2 - 3 } \cline { 5 - 6 } Leg & \multicolumn{2}{c}{ Start } & End & Start & End \\
\hline AB & $25.904^{\circ} \mathrm{N}-10.586^{\circ} \mathrm{W}$ & $25.904^{\circ} \mathrm{N}-9.539^{\circ} \mathrm{W}$ & & $09: 50$ & $09: 59$ \\
$\mathrm{CD}$ & $25.726^{\circ} \mathrm{N}-9.527^{\circ} \mathrm{W}$ & $25.740^{\circ} \mathrm{N}-10.538^{\circ} \mathrm{W}$ & & $10: 02$ & $10: 11$ \\
EF & $25.555^{\circ} \mathrm{N}-10.522^{\circ} \mathrm{W}$ & $25.571^{\circ} \mathrm{N}-9.535^{\circ} \mathrm{W}$ & & $10: 13$ & $10: 22$ \\
$\mathrm{GH}$ & $25.396^{\circ} \mathrm{N}-9.518^{\circ} \mathrm{W}$ & $25.400^{\circ} \mathrm{N}-10.541^{\circ} \mathrm{W}$ & & $10: 25$ & $10: 34$ \\
IJ & $25.221^{\circ} \mathrm{N}-10.456^{\circ} \mathrm{W}$ & $25.220^{\circ} \mathrm{N}-9.497^{\circ} \mathrm{W}$ & & $10: 37$ & $10: 45$ \\
JI & $25.214^{\circ} \mathrm{N}-9.573^{\circ} \mathrm{W}$ & $25.209^{\circ} \mathrm{N}-10.530^{\circ} \mathrm{W}$ & & $10: 52$ & $11: 01$ \\
$\mathrm{HG}$ & $25.373^{\circ} \mathrm{N}-10.467^{\circ} \mathrm{W}$ & $25.370^{\circ} \mathrm{N}-9.527^{\circ} \mathrm{W}$ & & $11: 03$ & $11: 11$ \\
FE & $25.537^{\circ} \mathrm{N}-9.563^{\circ} \mathrm{W}$ & $25.540^{\circ} \mathrm{N}-10.562^{\circ} \mathrm{W}$ & & $11: 14$ & $11: 23$ \\
DC & $25.703^{\circ} \mathrm{N}-10.536^{\circ} \mathrm{W}$ & $25.704^{\circ} \mathrm{N}-9.552^{\circ} \mathrm{W}$ & & $11: 26$ & $11: 34$ \\
BA & $25.869^{\circ} \mathrm{N}-9.596^{\circ} \mathrm{W}$ & $25.868^{\circ} \mathrm{N}-10.553^{\circ} \mathrm{W}$ & & $11: 37$ & $11: 46$ \\
\hline
\end{tabular}

the aircraft campaign in June 2011, 1 month after the intense rainfall period.

[15] Three research flights dedicated to the aims of RAIN4DUST were performed during June 2011: 11 June 2011 (flight number fs110013), 16 June 2011 (flight number fs110018), and 23 June 2011 (flight number fs110026). All three flights followed similar flight tracks as shown in Figure 1 schematically. On 11 June 2011, atmospheric conditions for morning dust emission following the break-down of the nocturnal LLJ were the best, and the observations capture the evolution of dust emission over time and space in the vicinity of the developing convective boundary layer well. We focus on observations from this flight in the remainder of the paper.

\section{Aircraft Measurements, Satellite Observations, and Model Simulations}

[16] Measurements from the LNG (LEANDRE Nouvelle Generation) lidar, ground camera, and dropsondes aboard the F20 aircraft are used and discussed in this study. Throughout the flight over the research domain, the aircraft was flying constantly at flight level FL320, which correspond to an approximate flight altitude of $11 \mathrm{~km}$ above ground level (agl). In addition to the measurements, satellite retrievals providing information on the atmospheric column dust load, and simulations from the mesoscale models AROME and Meso-NH are analyzed.

\subsection{Lidar}

[17] Airborne multiwavelength backscatter lidar has proven to be a powerful technique to detect dust plumes and characterize their properties [Ansmann et al., 2011]. In order to detect dust uplift over complex terrain and near-source dust transport, the LNG lidar was used. During the Fennec campaign, the system was operated in backscatter mode with two elastic channels at 1064 and $532 \mathrm{~nm}$. Energies of 10 and $50 \mathrm{~mJ}$ were emitted at these two wavelengths, respectively, at a $20 \mathrm{~Hz}$ repetition rate with a full angle divergence of the laser of $4 \mathrm{mrad}$ at $532 \mathrm{~nm}$ and $6.5 \mathrm{mrad}$ at $1064 \mathrm{~nm}$. For analysis, the acquired data are averaged over $10 \mathrm{~s}$ (200 shots) in order to reach a signal to noise ratio above 100 , which is necessary to detect the vertical distribution of dust and retrieve aerosol extinction profiles.

[18] The profiles of atmospheric extinction coefficient at $532 \mathrm{~nm}$ are retrieved using a standard lidar inversion technique [Fernald et al., 1972; Cuesta et al., 2008]. The profiles of molecular extinction coefficient used in the inversion procedure are obtained from molecular density profiles computed using temperature and pressure data from dropsondes released during the flight [Bodhaine et al., 1999]. The aerosol backscatter-to-extinction ratio (BER) used for the inversion is considered to be constant with altitude and has a value of $0.0205 \mathrm{sr}^{-1}$, which is in good agreement with values derived at $532 \mathrm{~nm}$ from airborne and ground-based lidar systems over Morocco during the SAMUM-1 (Saharan Mineral Dust Experiment) campaign [Heintzenberg, 2009] as well as with the values found in the non-Sahel regions of northern Africa based on a 6 year climatology using the airborne lidar CALIOP (Cloud-Aerosol Lidar with Orthogonal Polarization) [Schuster et al., 2012]. Above the dust layer, at $9.5 \mathrm{~km}$ agl, a backscatter-to-extinction ratio of 1 is considered, consistent with the assumption that all of the signal originates from molecular backscatter. In the following, we will show and discuss particulate extinction coefficient (PEC) profiles and aerosol optical depth (AOD) at $532 \mathrm{~nm}$ between the surface and $2 \mathrm{~km}$ agl obtained from the PEC profiles integrated between 0 and $2 \mathrm{~km}$ agl. As the uncertainty on the BER is estimated to $\pm 0.001 \mathrm{sr}^{-1}$, an uncertainty of the order of $15 \%$ can be assumed for the lidar-derived PEC and AOD values.

\subsection{MSG SEVIRI Aerosol Optical Depth}

[19] Aerosol optical depths over desert terrain retrieved from satellite observations provide useful information on the atmospheric column dust loadings near the dust source regions. In this study here we use the Meteosat Second Generation (MSG) Spinning Enhanced Visible and InfraRed Imager (SEVIRI) AOD product developed by Brindley and Russell [2009] and recently improved by Banks and Brindley [2013]. Due to the geostationary location of the MSG satellite and the relatively high sampling interval of the SEVIRI instrument, AOD fields at $550 \mathrm{~nm}$ wavelength are available at half-hourly resolution during daylight (06-16 UTC) covering North Africa with a spatial resolution of approximately $4 \mathrm{~km}$ over the research domain. A detailed description of the AOD product retrieval and results of a 3 year evaluation period is given in Banks and Brindley [2013]. Here, the updated retrieval, their version 2 , is used. For the study area, an uncertainty of the order of $5-10 \%$ is estimated.

\subsection{Ground Camera}

[20] Monochrome (black/white) aerial photographs of the ground surface are taken by the Basler SCA 1400-30FM 
camera mounted downward facing. Pictures with a resolution of $1392 \times 1040$ pixel were taken every second. A $9 \mathrm{~mm}$ lense (Fujion, 2/3") was used with an aperture of f/1.4. For flights on flight level FL320, each photograph covers a horizontal area of $3.3 \mathrm{~km} \times 4.4 \mathrm{~km}$ along the track.

\subsection{Dropsondes}

[21] Vaisala dropsondes of type RD94 were launched during the research flight. Tracks and measurements by the sonde were recorded by the Vaisala AVAPS GPS system aboard the F20 during the flight. The sondes measure in situ pressure, air temperature, dew point, relative humidity, wind speed and direction together with time and GPS position of the sonde.

\subsection{Numerical Modeling}

[22] Numerical simulations from two mesoscale atmospheric model systems including a dust emission and transport scheme are available for the Fennec/RAIN4DUST period in June 2011: The AROME model and the Meso-NH research model. Meso-NH is a mesoscale research model, whereas AROME is an operational forecast model used at Météo France. Both models differ in their dynamical core with the Meso-NH parametrization following the Eulerian description, and AROME following the Lagrangian description. To meet the demands of a research model and forecast model respectively, the model initialization with boundary conditions is solved differently. Both model systems include similar surface schemes and dust modules.

[23] The meteorological overview is discussed using geopotential and wind fields at $925 \mathrm{hPa}$ provided by the ECMWF (European Centre for Medium-Range Weather Forecasts) ERA-Interim reanalysis data set.

\subsubsection{ECMWF ERA-Interim Reanalysis}

[24] For an overview of the synoptic situation, fields of geopotential height and wind at $925 \mathrm{hPa}$ are taken from the ECMWF ERA-Interim reanalysis data set [Dee et al., 2011] for 06 UTC and 12 UTC on 11 June 2011. The fields are provided on a horizontal grid with a spectral resolution of T255 and were interpolated to a $1^{\circ} \times 1^{\circ}$ grid.

\subsubsection{AROME Model}

[25] The numerical weather prediction model AROME [Seity et al., 2011] is a nonhydrostatic regional model that takes advantage of both the IFS/ARPEGE/Aladin system (dynamical adiabatic core, data assimilation, software) [Courtier et al., 1994] and the Meso-NH research system [Lafore et al., 1998] for most of its physical parametrization such as micro-physics, turbulence, shallow convection, and surface processes. AROME is a spectral model and uses a two time-level, semi implicit, semi Lagrangian discretization scheme on an Arakawa A-grid. The Dust Entrainment and Deposition (DEAD) model [Zender et al., 2003; Grini et al., 2006] is coupled online to the atmosphere module.

[26] AROME was operated in its forecast mode during the entire Fennec field campaign period in June 2011. Initial and boundary data were taken from operational large-scale ARPEGE simulations for $18 \mathrm{UTC}$. The forecast fields are available at $5 \mathrm{~km}$ horizontal grid spacing for a domain covering the region between $8^{\circ}$ to $35^{\circ} \mathrm{N}$ and $23^{\circ} \mathrm{W}$ to $40^{\circ} \mathrm{E}$. The size of the domain represents all dust sources of known relevance for the RAIN4DUST research domain. Simulations were performed at 41 vertical levels. Deep convection was calculated explicitly due to the relatively high spatial resolution.

\subsubsection{Meso-NH Model}

[27] The Meso-NH [Lafore et al., 1998] was run over a domain of $4800 \mathrm{~km} \times 2560 \mathrm{~km}$ covering northern Africa between $13.0^{\circ} \mathrm{N}$ and $35.9^{\circ} \mathrm{N}$ and $18.8^{\circ} \mathrm{W}$ and $28.8^{\circ} \mathrm{E}$ with a $5 \mathrm{~km}$ grid spacing. The vertical grid consists of 70 levels and has a spacing varying from $60 \mathrm{~m}$ close to the ground to $600 \mathrm{~m}$ in the free troposphere. The initial and boundary conditions were provided by ECMWF analysis and forecasts issued at 00 UTC on 11 June 2011. The model includes a turbulence parametrization, a mixed-phase bulk microphysical scheme, a sub-grid cloud cover and condensate content scheme, and the same dust scheme, DEAD, as in AROME. A sensitivity simulation was run using the same parametrization and initial and boundary conditions but with a $1 \mathrm{~km}$ grid spacing. Due to the high computational cost, the simulation was performed over a smaller domain of $720 \mathrm{~km} \times 640 \mathrm{~km}$ covering the area of interest between $23.6^{\circ} \mathrm{N}$ and $29.3^{\circ} \mathrm{N}$ and $14.6^{\circ} \mathrm{W}$ and $7.4^{\circ} \mathrm{W}$. For further details on the parametrization used in the simulations, the reader is referred to Chaboureau et al. [2011].

\subsubsection{Dust Model}

[28] The Dust Entrainment And Deposition (DEAD) model [Zender et al., 2003; Grini et al., 2006] is implemented into the Interaction Soil Biosphere Atmospher (ISBA) land surface parametrization scheme [Noilhan and Mahfouf, 1996] that is part of the surface scheme SURFEX, which is used for Meso-NH and AROME. Details on the implementation of DEAD in SURFEX are given by Grini et al. [2006].

[29] Dust emission is prescribed assuming a globally uniform soil texture and an abundance of saltation (particle diameter $>60 \mu \mathrm{m}$ ) [Zender et al., 2003]. Additional information on the erodible fraction is provided by the $1 \mathrm{~km}$ resolution ECOCLIMAP data set [Masson et al., 2003], in particular the classes COVER004 and COVER005 for bare soil and rock soil, respectively. Information on the soil fractions, in particular sand, silt, and clay fractions, are taken from the Food and Agriculture Organization of the United Nations (FAO) soil database (10 km resolution).

[30] In order to simulate dust emission, the particle saltation needs to be predicted before dust emission fluxes can be calculated. This is performed using the drag-partitioning scheme as described by Marticorena and Bergametti [1995], which parameterizes the turbulent momentum transport from the near-surface boundary layer onto the soil surface. Thereby, wind friction speed is calculated depending on the surface drag properties, in particular described by the surface roughness length $\mathrm{z}_{0}$. Here constant values of $\mathrm{z}_{0}$ are considered with $\mathrm{Z}_{0}=100 \mu \mathrm{m}$ for bare soil and $\mathrm{z}_{0}=200 \mu \mathrm{m}$ for rock soil. The impact of soil moisture content on the threshold friction velocity for saltation is calculated following Fécan et al. [1999]. The predicted saltation flux (horizontal saltation flux) is then weighted by the fraction of sand provided by the soil type [Grini et al., 2006]. Finally, the horizontal saltation flux is transformed into the vertical mass flux following Marticorena and Bergametti [1995]. Thereby, a uniform value for the clay fraction is applied for DEAD to determine the sandblasting mass efficiency [Zender et al., 2003]. The chosen factor, $\alpha$, is model dependent as the vertical resolution and the parametrization of 
a)

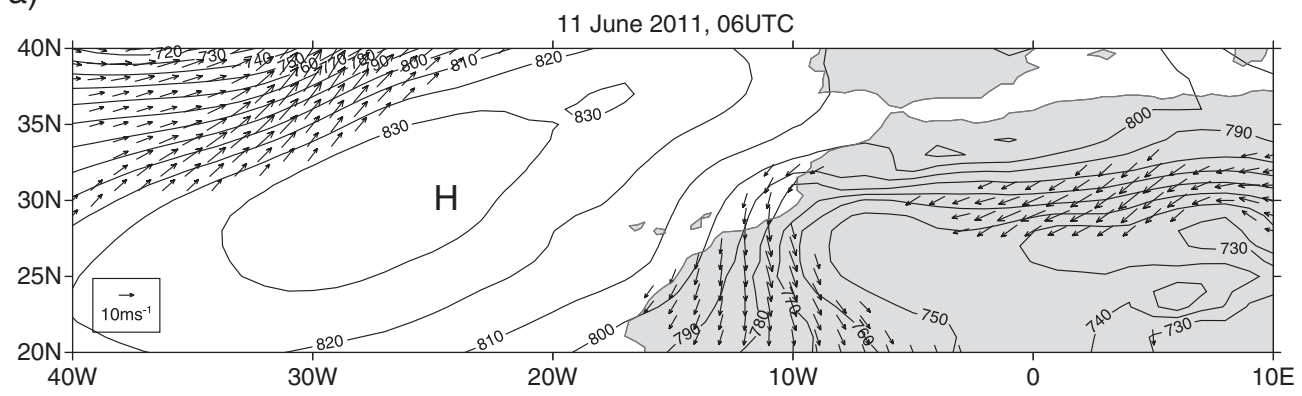

b)

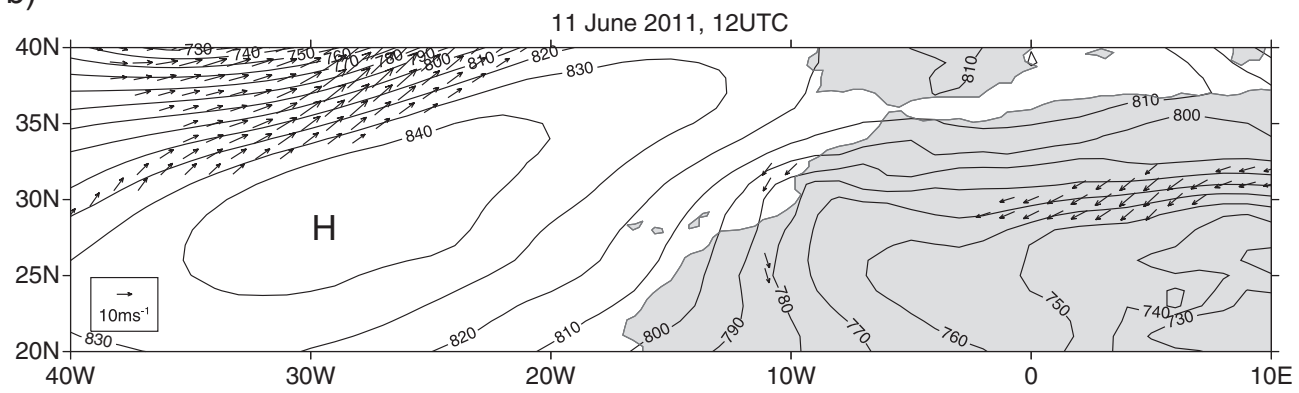

Figure 2. Synoptic overview for 11 June 2011 at (a) 06 UTC and (b) 12 UTC. Contour lines give geopotential height at $925 \mathrm{hPa}$ in geopotential decameters (gpdm), winds stronger than $10 \mathrm{~ms}^{-1}$ at $925 \mathrm{hPa}$ are indicated by vectors. Fields are taken from the ECMWF ERA-Interim reanalysis data set. "H" marks the center of the Azores high.

the conversion of the dust emission flux (horizontal saltation flux into vertical mass flux) differs between the models. For MesoNH, the $\alpha$-factor was calibrated for the June 2011 period using AERONET observations. AROME was tuned for the June 2006 period using observations made during the AMMA campaign [Kocha et al., 2011].

[31] Dust particle size distributions are parameterized following the log-normal aerosol model ORILAM [Tulet et al., 2005,2008 ] coupled to the atmospheric core. The initial dust size distribution is given by three modes as described by Alfaro and Gomes [2001] with median radii of $0.32 \mu \mathrm{m}$, $1.73 \mu \mathrm{m}$, and $4.33 \mu \mathrm{m}$ and standard deviations of $1.7,1.6$, and 1.5 , respectively. These modes evolve during the simulation time by several processes such as sedimentation, surface deposition, and scavenging. Dust transport as well as dry and wet deposition is calculated within ORILAM considering three log-normal dust particle size modes that are derived from measurements during the AMMA (African Monsoon Multidisciplinary Analysis) campaign [Crumeyrolle et al., 2011; Tulet et al., 2010]. Radiative properties of dust such as extinction coefficient, asymmetry factor, and single scattering albedo are calculated within ORILAM that is coupled online to the ECMWF radiation scheme implemented in Meso-NH and AROME [Tulet et al., 2008; Aouizerat et al., 2010]. Aerosol-cloud interactions including impact-scavenging are parameterized following a kinetic mass approach as described in Tulet et al. [2010]. The refractive index of the dust aerosols is taken from AERONET (AErosol RObotic NETwork) inversions [Dubovik et al., 2002].

[32] The soil texture relevant for the dust emission module is characterized by $43 \%$ sand, $34 \%$ silt, and $23 \%$ clay, according to the Food and Agriculture Organization of the
United Nations (FAO) soil database. Due to the horizontal resolution of $10 \mathrm{~km}$ for the FAO data set, mean values for sand, silt, and clay fractions are constant over the rather small simulation domain. Thus, without increasing the horizontal resolution of the soil data set, spatial distribution in soil texture is homogeneous.

\section{The 11 June 2011 Dust Emission Case}

\subsection{Meteorological Overview}

[33] On 11 June 2011, the atmospheric circulation over north West Africa was dominated by an anticyclonic circulation related to the Azores High centered west of the Madeira Islands (Figure 2). Associated with this anticyclonic flow, maritime air was advected into continental West Africa by northerly winds. At night, this advection of cool, moist air stabilized the boundary layer and a sharp inversion developed above the nocturnal boundary layer (NBL) and decoupled the residual PBL from the surface allowing for the LLJ to accelerate within the residual layer above the nocturnal inversion.

[34] Winds at $925 \mathrm{hPa}$, which is approximately the level of the LLJ, were significantly stronger at 06 UTC (Figure 2) than at 12 UTC. Winds of more than $15 \mathrm{~m} \mathrm{~s}^{-1}$ are strong enough to initiate dust emission once mixed down to the surface. At 12 UTC, when a deep PBL had already developed, winds of less than $10 \mathrm{~m} \mathrm{~s}^{-1}$ were evident. Although the pressure gradients at $925 \mathrm{hPa}$ were similar at 06 and $12 \mathrm{UTC}$, the significantly lower winds at 12 UTC indicate that the $925 \mathrm{hPa}$ level was within the PBL at this time. In contrast, at $06 \mathrm{UTC}$ the $925 \mathrm{hPa}$ level was situated above the NBL within the residual layer where the LLJ had developed. 


\subsection{Observed Boundary Layer Characteristics}

[35] Boundary layer characteristics that provide evidence for the presence of a nocturnal LLJ were retrieved from dropsondes. During the flight on 11 June 2011, four dropsondes were released along $10^{\circ} \mathrm{W}$ as shown by filled circles in Figure 1b. Vertical profiles of potential temperature, water vapor mixing ratio (WVMR), and wind, as shown in Figure 3, characterize the development of the PBL. Dropsonde D1 shows a bias in temperature and therefore is not further considered. Overall, the in situ measurements represent the decay of the nocturnal LLJ layer and the development of the convective PBL during the course of the observations. The potential temperature and the WVMR indicate the stability of the PBL. Well-mixed layers are characterized by a constant potential temperature and WVMR. A capping inversion at the top of the PBL is evident from the sharp decrease in WVMR. The well-mixed PBL layer is also characterized by a homogeneous aerosol distribution as shown by Figure 4 and discussed below. The relative humidity increases linearly with height within the well-mixed layer due to the lapse rate. Within the PBL, the remnant of a nocturnal LLJ can be identified. During the night, the nocturnal LLJ has formed within the residual BL above the temperature inversion that separates the NBL from the residual layer. This inversion decouples the residual BL from the surface and allows for the acceleration of the winds within lower residual layer to super-geostrophic velocities, forming the LLJ. With increasing turbulence and deepening PBL the next morning, the LLJ layer is finally coupled to the PBL. Momentum from the LLJ layer is mixed into the PBL and the LLJ becomes eroded. During this stage of decay, the lowlevel wind maximum associated with the LLJ is still present, but weaker and now within the growing PBL. This is present in the observations by the dropsonde $\mathrm{D} 2$, but it is absent in the wind profile measured by the dropsonde D3. There, the decay of the LLJ is already complete. The fourth sonde D4 (same location as D2 but $1 \mathrm{~h}$ later) measures some remnant of the LLJ, which can be described as a transition from the state observed by D2 (LLJ still present, but within PBL) to D3 (LLJ absent).

[36] All dropsondes observe a well-mixed PBL with increasing depth from $600 \mathrm{~m}$ at $25.75^{\circ} \mathrm{N}$ (D2) to $800 \mathrm{~m}$ at $25.3^{\circ} \mathrm{N}$ (D3) (Figure 3). The potential temperature and the WVMR within the PBL indicate a development with time and latitude. As the position of the sun above the horizon rises with time, solar heating increases as well, leading to increasing turbulence and temperature. Consequently, the potential temperature within the PBL increases as well as the depth of the PBL.

[37] Dropsondes D2, D3, and D4 (Figures 3a-3c) show an example of the development of the PBL and the degradation of the nocturnal LLJ layer not only with regard to time but also with regard to surface structure and albedo. The terrain over the research domain flattens with decreasing latitude as shown in Figure 1, and the surface structure becomes smoother as exemplified by the aerial images shown in Figure 5 for two of the valley systems. Surface heating and surface roughness influence the PBL. Comparing the three dropsondes with regard to time and space, the vertical profile measured by dropsonde D2 indicates a well-mixed PBL with a potential temperature of $298 \mathrm{~K}$ and a WVMR of $9 \mathrm{~g} \mathrm{~kg}^{-1}$ up to a height of $600 \mathrm{~m}$ agl. Within this layer,
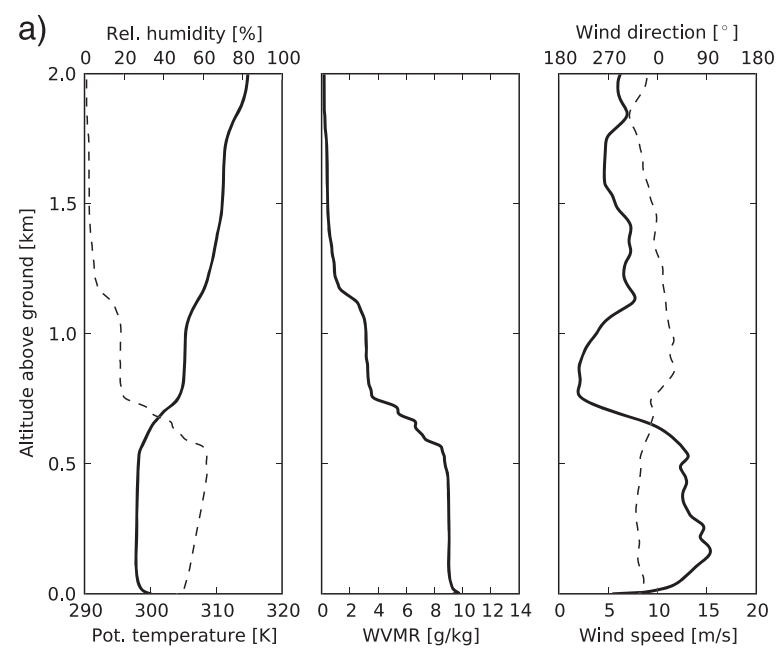

b) Rel. humidity [\%]
0
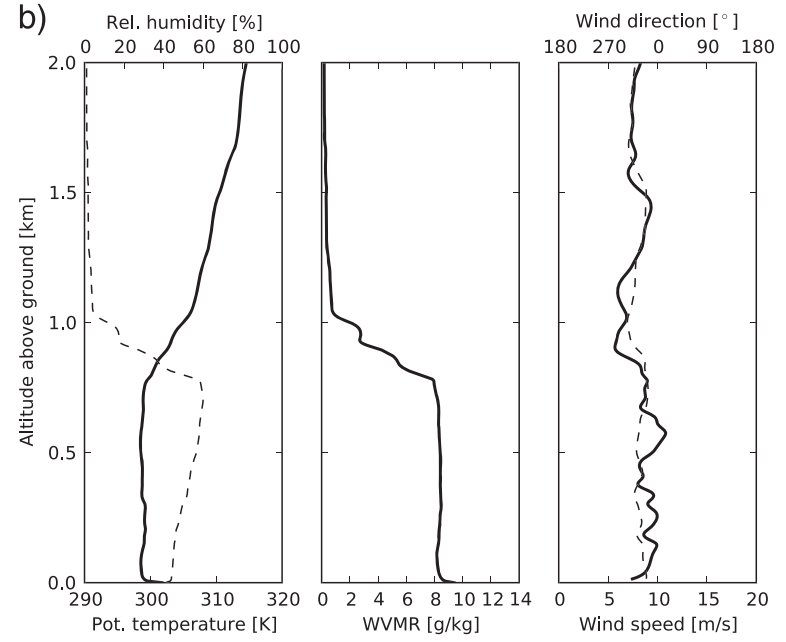

C) Rel. humidity [\%]
$\begin{array}{llllll}0 & 20 & 40 & 60 & 80 & 100\end{array}$

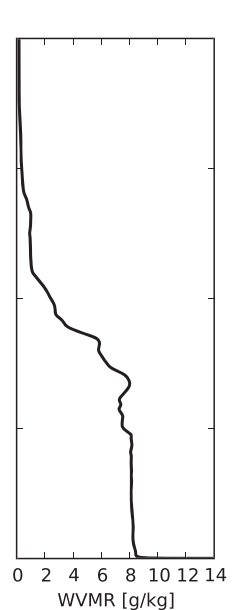

Wind direction $\left[{ }^{\circ}\right]$
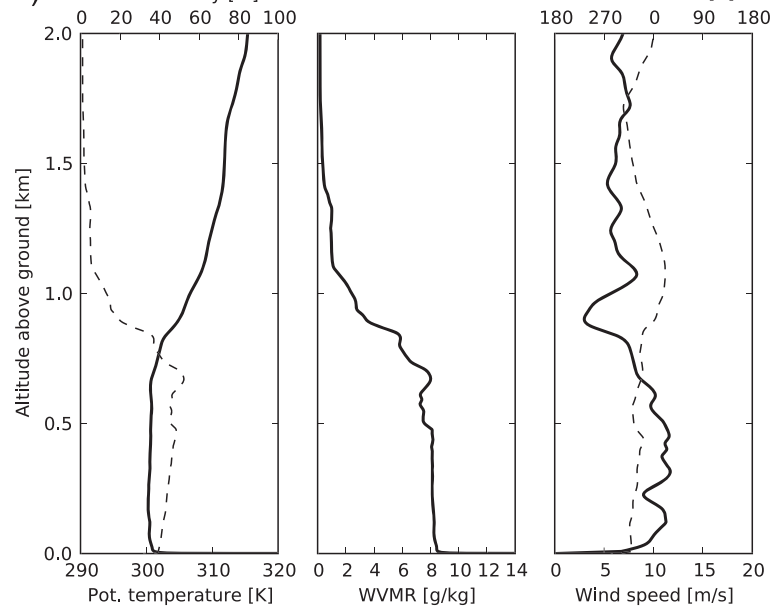

Figure 3. Vertical profiles of (left panels, solid line) potential temperature, (left panels, dashed line) relative humidity, (middle panel, WVMR) water vapor mixing ratio, (right panels, solid line) horizontal wind speed, and (right panels, dashed line) horizontal wind direction measured by dropsondes released at $10^{\circ} \mathrm{W}$ as shown in Figure 1. (a) Dropsonde D2 released at 10:18 UTC at $25.6^{\circ} \mathrm{N} 10.0^{\circ} \mathrm{W}$, (b) dropsonde D3 released at $10: 41 \mathrm{UTC}$ at $25.3^{\circ} \mathrm{N} 10.0^{\circ} \mathrm{W}$, and (c) dropsonde D4 released on the return at 11:19 UTC at $25.6^{\circ} \mathrm{N}$ $10.0^{\circ} \mathrm{W}$ (same position as dropsonde $\mathrm{D} 2$ ). 

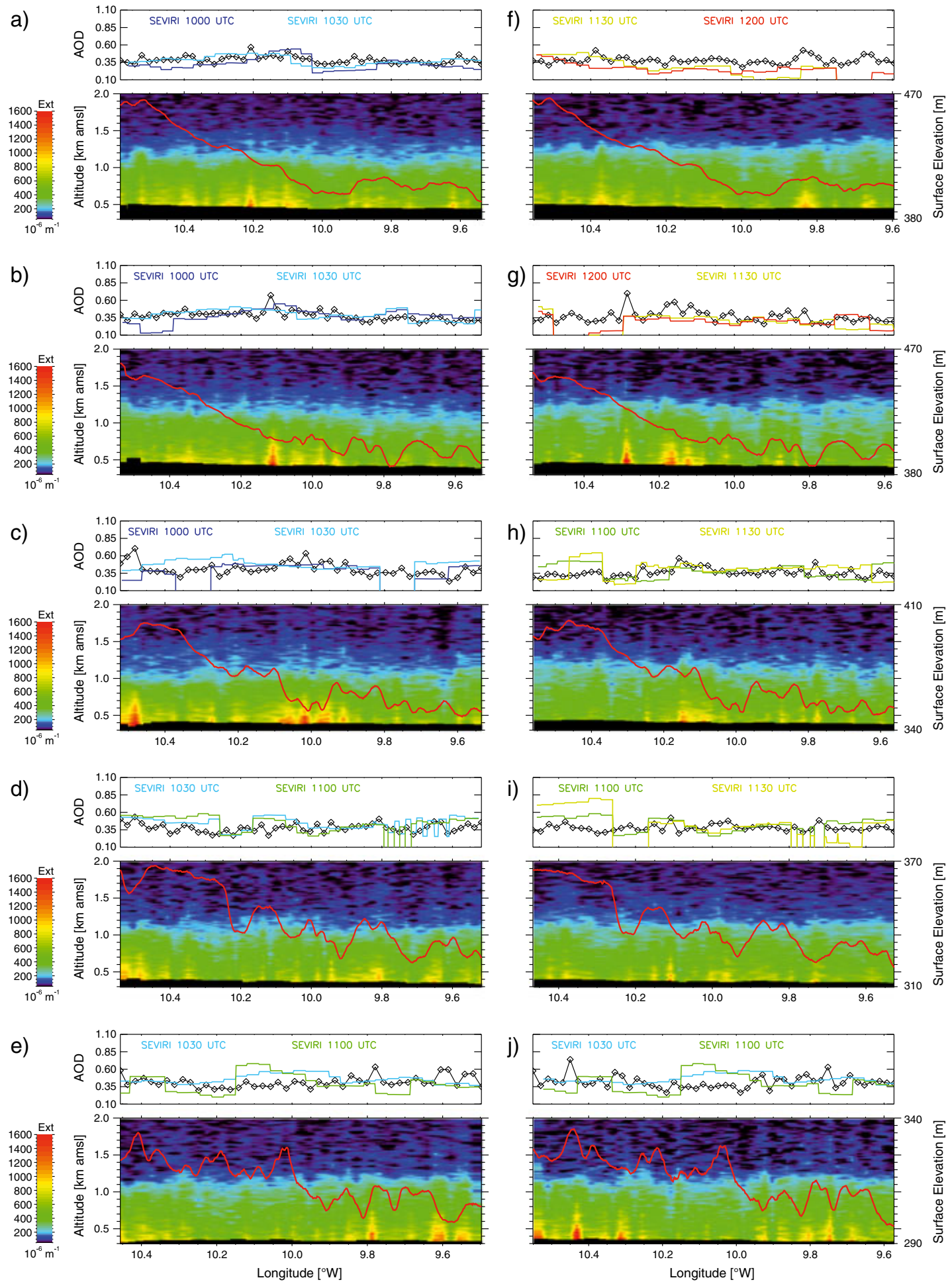

Figure 4. Particulate extinction coefficient (PEC) retrieved from airborne lidar measurements at $532 \mathrm{~nm}$ are given by colors. Terrain elevation is represented by solid red line. AOD values calculated from PEC for the lowest $2 \mathrm{~km}$ (diamonds) representing the dust content within the boundary layer are shown in separate panels above each PEC figure together with MSG SEVIRI AODs (bold line) for the closest retrieval time. Different observation times are indicated by different colors: blue - 10:00 UTC, green - 10:30 UTC, lightgreen - 11:00 UTC, orange - 11:30 UTC, red - 12:00 UTC. Please note that due to the motion component of the aircraft and the sampling interval of the lidar instruments, local AOD maxima may be offset in flight direction compared to the topography and MSG SEVIRI AOD. (a) leg $\mathrm{AB}$ at $25.9^{\circ} \mathrm{N}$, (b) leg $\mathrm{CD}$ at $25.75^{\circ} \mathrm{N}$, (c) leg EF at $25.6^{\circ} \mathrm{N}$, (d) leg GH at $25.45^{\circ} \mathrm{N}$, (e) leg IJ at $25.3^{\circ} \mathrm{N}$, and on the return f) leg BA at $25.9^{\circ} \mathrm{N}$, (g) leg DC at $25.75^{\circ} \mathrm{N}$, (h) leg FE at $25.6^{\circ} \mathrm{N}$, (i) leg HG at $25.45^{\circ} \mathrm{N}$, and (j) leg JI at $25.3^{\circ} \mathrm{N}$. Altitude is given in $\mathrm{km}$ amsl. 
a)

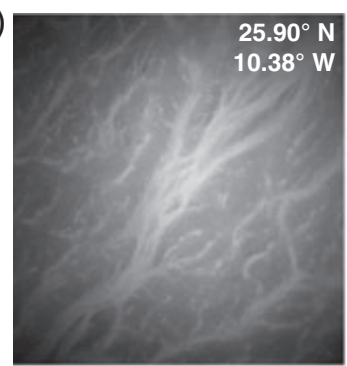

b)

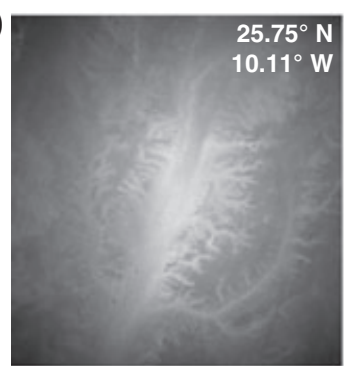

c)

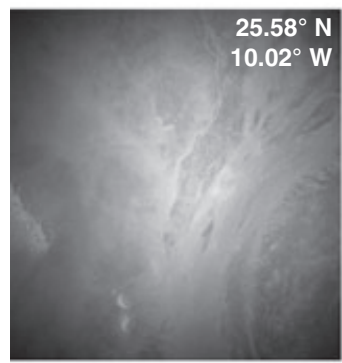

d)

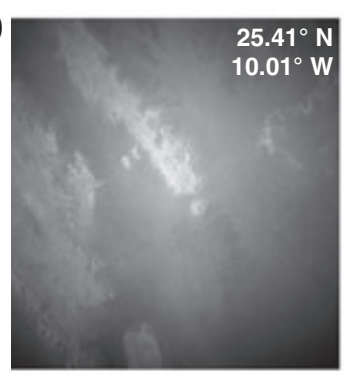

e)

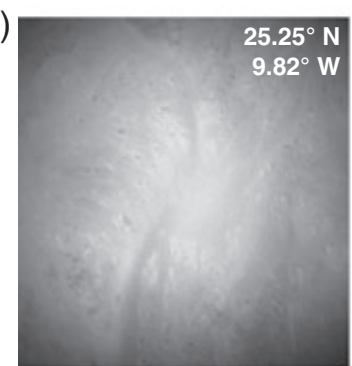

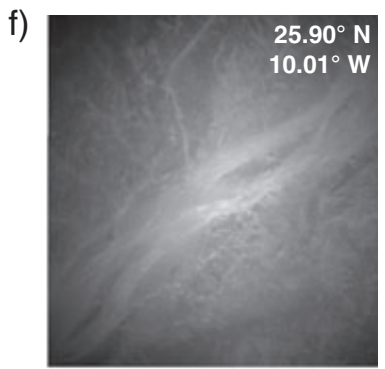

g)

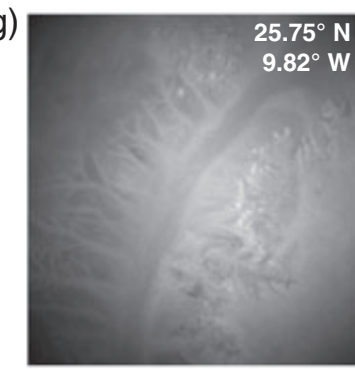

h)

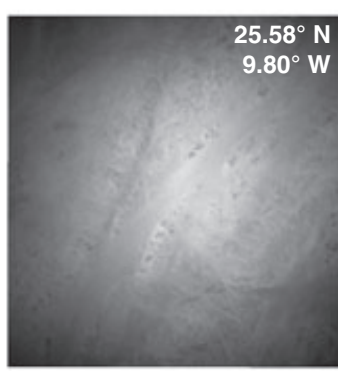

i)

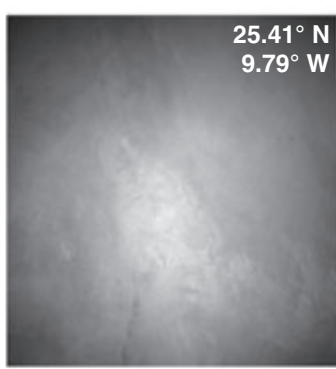

j)

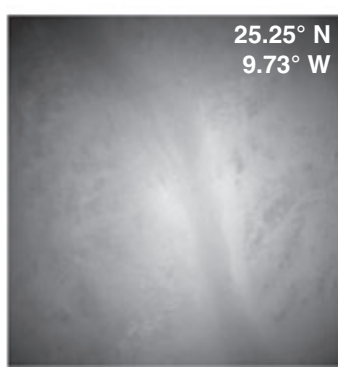

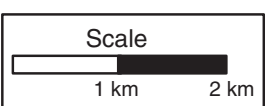

Figure 5. Aerial photographs taken by downward facing ground camera aboard the F20 showing the decrease in surface ruggedness from north to south. Figures of each row are taken along one track, with first row showing two photographs along leg $\mathrm{AB} / \mathrm{BA}$ and last row showing two photographs along leg IJ/JI. Locations of photographs along each leg are chosen to show snap shots of surface characteristics of the two main drainage systems being present over all legs.

remnants of a nocturnal LLJ with a wind speed maximum of $15 \mathrm{~m} \mathrm{~s}^{-1}$ at $200 \mathrm{~m} \mathrm{agl}$ are evident. About $1 \mathrm{~h}$ later, the PBL has developed a depth of approximately $800 \mathrm{~m}$. The boundary layer was heated by $2 \mathrm{~K}$ to $300 \mathrm{~K}$ and has a WVMR of $8 \mathrm{~g} \mathrm{~kg}^{-1}$ (i.e., drier PBL conditions). The nocturnal LLJ layer decayed with time as boundary layer turbulence eroded the wind speed maximum, distributing its momentum over the PBL depth. As described in the literature, this process is accompanied by sudden increase of surface winds and gustiness [e.g., Lenschow and Stankov, 1979]. Dropsonde D3 

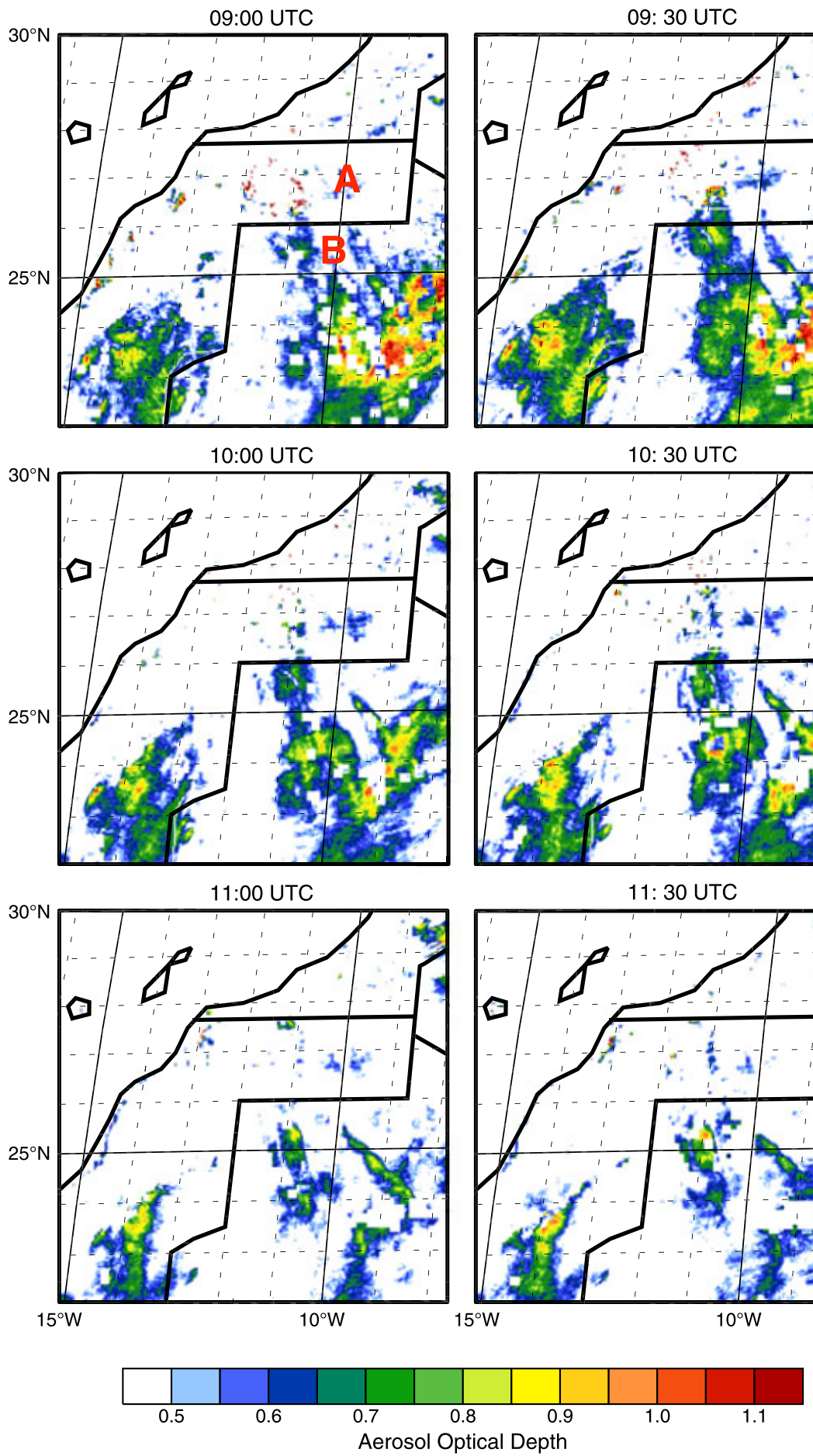

Figure 6. MSG SEVIRI AOD at $550 \mathrm{~nm}$ for 11 June 2011, 09:00 UTC to 11:30 UTC at half-hourly resolution. No AOD retrieval is available over the ocean. Labels " $\mathrm{A}$ " and "B" identify two areas of increased dustiness as discussed within the text.

that was released about $30 \mathrm{~km}$ further south shows an atmospheric profile indicating a PBL depth of about $800 \mathrm{~m}$, with a top marked by a sharp decrease in WVMR. The potential temperature within the PBL is at $299 \mathrm{~K}$ comparable to dropsonde D2, but no clear nocturnal LLJ can be identified for $\mathrm{D} 2$. There is a wind speed maximum observed at $600 \mathrm{~m}$ agl, which can be seen as the last remnants of a nocturnal LLJ eroded by increasing PBL turbulence.

\subsection{MSG SEVIRI AOD}

[38] MSG SEVIRI AOD images indicate the presence of airborne mineral dust over north West Africa (Figure 6). Due to the nighttime advection of air from the Atlantic, the level of background dustiness is low $(<0.2)$ on 11 June 2011. Dust plumes associated with an AOD of up to 1.0 develop from local dust emission during the morning with increasing AODs as shown in Figure 6 for 09:00-11:30 UTC at 
a)

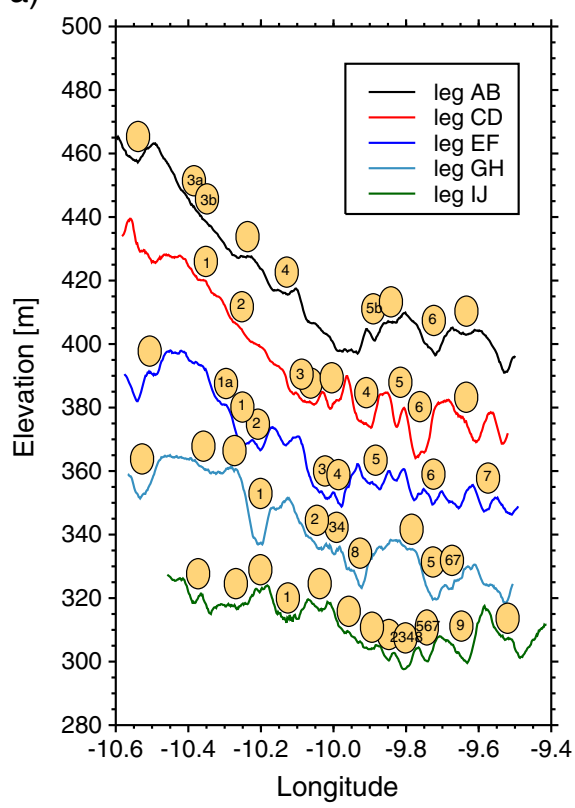

b)

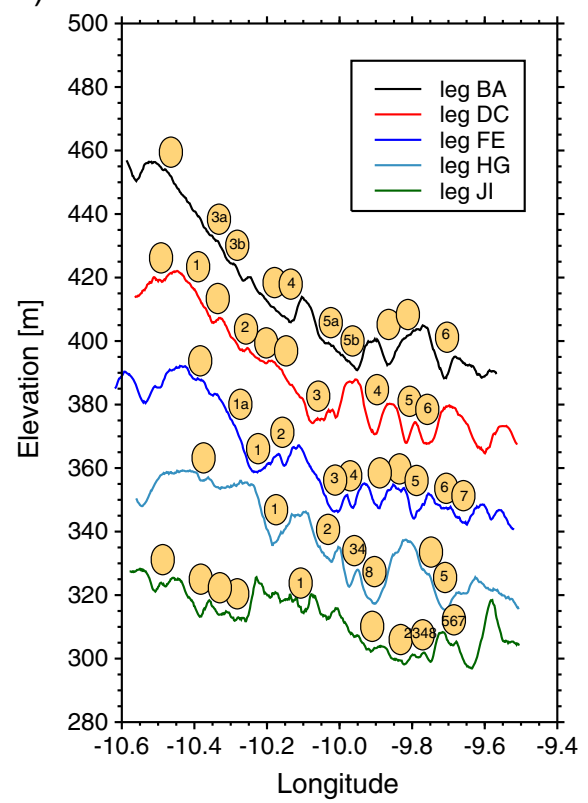

Figure 7. Elevation of terrain above sea level along the flight tracks. (a) Legs on the outbound flight and (b) legs on the return flight. Elevation is taken from the Shuttle Radar Topography Mission digital elevation data set shown at $90 \mathrm{~m}$ horizontal resolution interpolated with a $900 \mathrm{~m}$ running mean. The location of dust plumes observed by lidar measurements as shown in Figure 4 are indicated by orange ellipses. Connected valley systems are numbered.

half-hourly time slots. With respect to the research domain (cf. Figure 1), two areas of increased dustiness are of interest. First, the area over Western Saharan territories north of the Mauritanian-Western Saharan border labeled "A" in Figure 6 . This region lies upwind of the domain covered by the airborne measurements and therefore needs to be considered as source for dust transported into the research domain. Second, the mountain foothill area south of the MauritanianWestern Saharan border labeled "B" in Figure 6. The regions are separated by a meridional orientated mountain ridge and thus low level dust emitted north of the ridge is not advected into the aircraft research domain during the time of interest (morning hours until noon), although northerly winds are present (Figure 2).

[39] Analyzing the temporal evolution of these two regions of relatively high AODs, an increase of local AODs can be noted for the hours until 10:30 UTC. This can be explained by increasing atmospheric dust concentrations due to lasting dust emission in the presence of the downward mixing of the nocturnal LLJ. Dropsonde observations of the mixing state of the atmosphere and the vertical wind distribution further indicate that the PBL is well-mixed by this time of the day, and the remnants of the LLJ are diminished (cf. Figure 3). Thus, local dust emission fluxes decrease, and local dust plumes migrate within the regional airflow. While horizontal distribution of dust concentrations at near-surface levels is highly heterogeneous with high concentrations over source regions during the active dust uplifting phase, horizontal dust concentrations disperse during transport and lead to broader and lower concentration maxima.

[40] Over the domain covered by the aircraft observations, two meridional orientated bands of increased AOD (up to 0.8 ) can be identified from Figure 6. One band is located over the western margins of the domain, a second band is situated east of $10^{\circ} \mathrm{W}$. The horizontal variability of dust AOD with regard to the topography will be discussed for the individual legs together with the airborne lidar observations in section 4.4

\subsection{Airborne Observation of Dust Emission}

[41] Due to the location of the research area and the prevailing northerly wind direction, it can be assumed that all aerosols within the PBL are of terrigenous origin, i.e., mineral dust. The highest lidar-derived PECs are retrieved for the PBL. The aircraft overpass before noon, the decaying LLJ, and the advection of pristine air from the ocean suggest that dust within the PBL originates from local dust sources.

[42] The vertical distribution of PEC that is directly linked to the atmospheric dust concentration (as aerosols from other sources such as soot are unlikely) is shown in Figure 4 for each leg, which covers a distance of approximately $120 \mathrm{~km}$ (see Table 1 for details on legs). The AOD calculated for the first $2 \mathrm{~km}$ agl is also given in Figure 4 together with the AODs retrieved from the MSG SEVIRI observations. Considering the PEC for the first $2 \mathrm{~km}$ agl only, the AOD can be directly related to local dust emission. As the air above the PBL is rather aerosol free, the MSG SEVIRI AOD can be assumed to be close to the AOD calculated from the lidar observations. The topography along the flight track is overlaid in Figure 4 allowing for the colocation of peaks in PEC distribution with the topography.

[43] Due to local dust emission, the dust concentration and therefore the retrieved PEC is highest within the PBL. A sharp decrease in PEC at about $1 \mathrm{~km}$ agl marks the top of the PBL. Due to the ongoing development of the PBL as 
a)

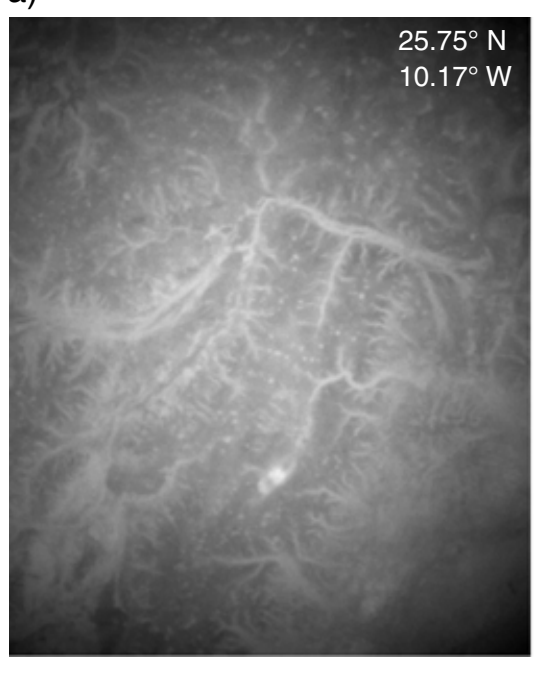

c)

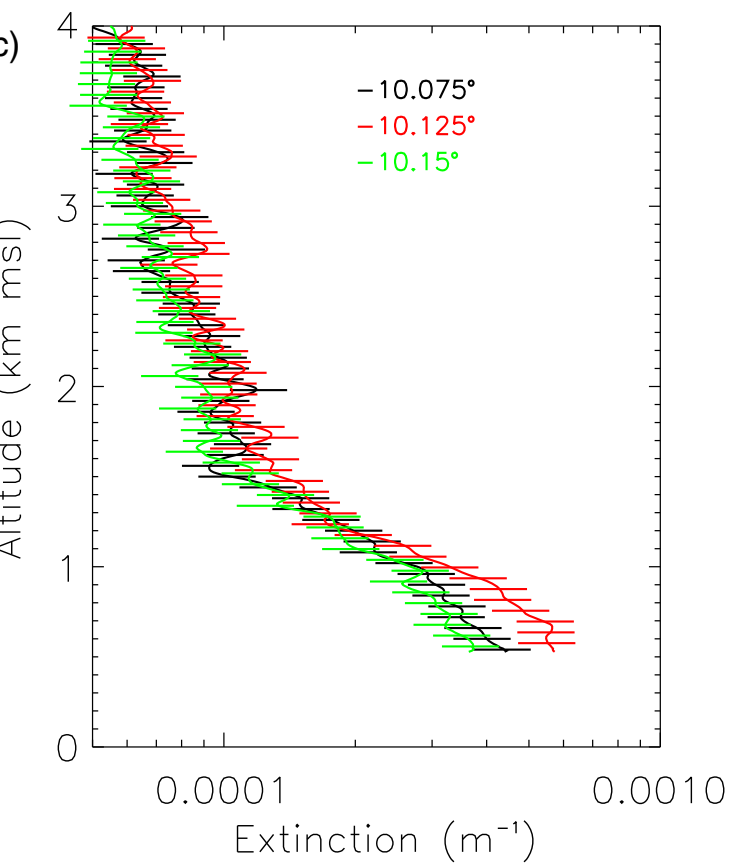

b)

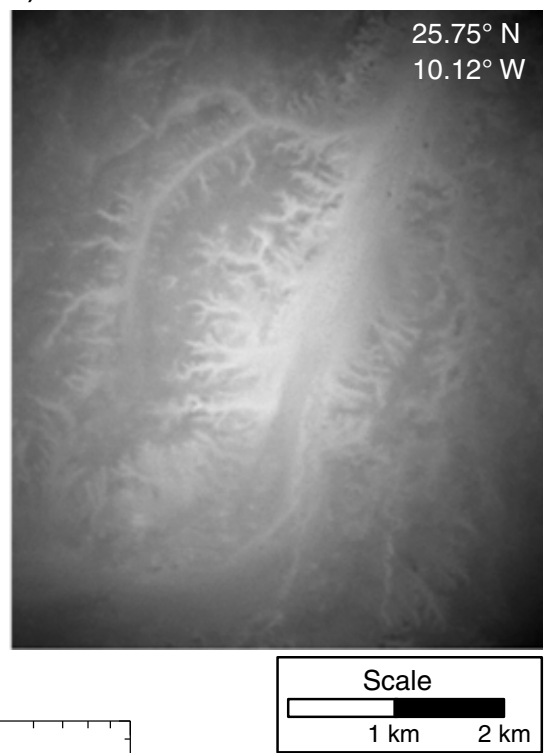

Figure 8. (a) and (b) Aerial photographs for two vertical profiles of valley " 3 " region along flight leg CD. (c) Vertical profiles of extinction coefficient for three locations: the valley itself at longitude $10.125^{\circ} \mathrm{W}$ and two adjacent locations uphill at $10.15^{\circ} \mathrm{W}$ and $10.075^{\circ} \mathrm{W}$. Horizontal bars represent uncertainty on the presented profile.

evident from the dropsondes (see section 4.2), the depth of the PBL increases over the time of the flight by $200-300 \mathrm{~m}$. Although background dustiness is evident for the PBL, this can be explained by dispersion of entrained dust due to turbulent processes within the deepening PBL, local hot spots in terms of increased PEC are observed within the PBL over each leg of the flight.

[44] The horizontal distribution of dust concentration and PEC maxima, respectively, provides information on the location of dust sources. The comparison between boundary layer PEC and topography suggests that some high dust concentrations can be placed over or nearby valleys. Not all valleys are necessarily acting as a dust source at the same time. When comparing horizontal distribution of dust concentrations and elevation, uncertainties due to the characteristics of the lidar observation need to be taken into account. The beam width, the ground speed of the aircraft, and the temporal averaging of lidar profiles, as part of data post-processing and noise reduction, lead to a smear-out of sharp, isolated dust concentration maxima as expected for narrow valleys. Thus, local hot spots in dust concentrations may appear at a shifted geographical position along the flight track, and the concentration maximum may be smeared out.

[45] The visually identified hot spots obtained from the PEC retrievals in Figure 4 are summarized schematically in Figure 7 and set in relation to the surface topography. Valleys and endorheic systems that are crossed by the flight track several times at different latitudes are numbered for better 
a) 11 June 201109 UTC ( $t+15)$ AROME $\Delta x=5 \mathrm{~km}$

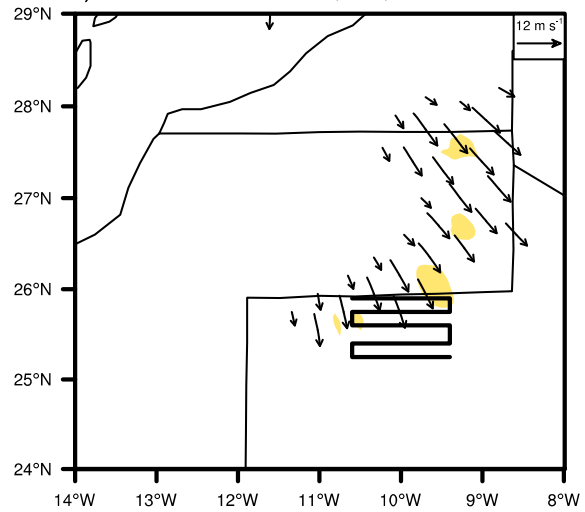

C) 11 June 201109 UTC ( $\mathrm{t}+9)$ Meso-NH $\Delta \mathrm{x}=5 \mathrm{~km}$

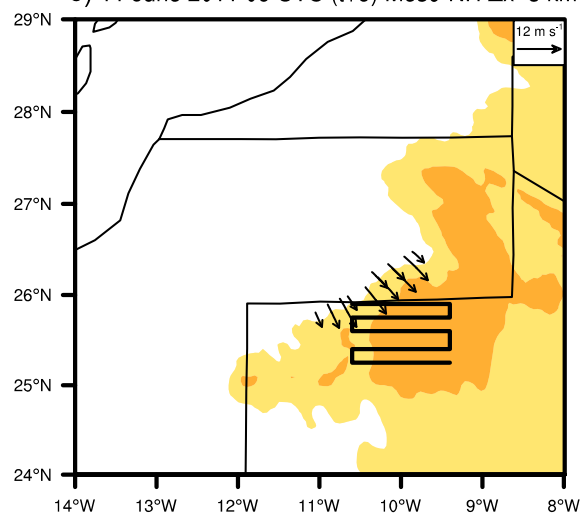

e) 11 June 201109 UTC ( $t+9)$ Meso-NH $\Delta x=1 \mathrm{~km}$

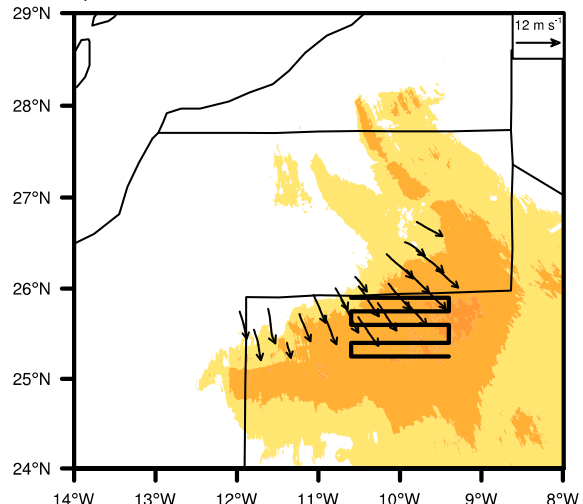

b) 11 June 201112 UTC ( $t+18)$ AROME $\Delta x=5 \mathrm{~km}$

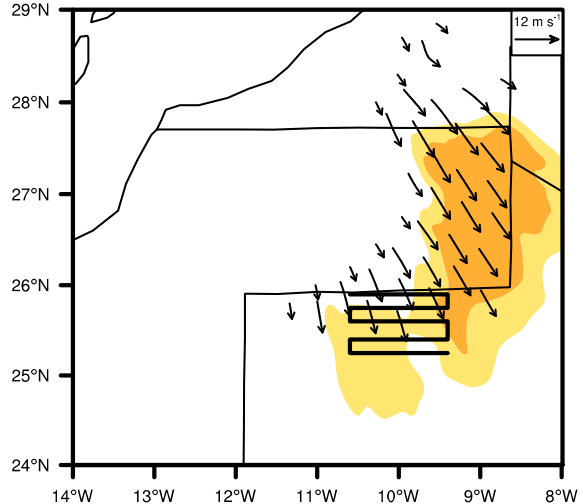

d) 11 June 201112 UTC (t+12) Meso-NH $\Delta x=5 \mathrm{~km}$

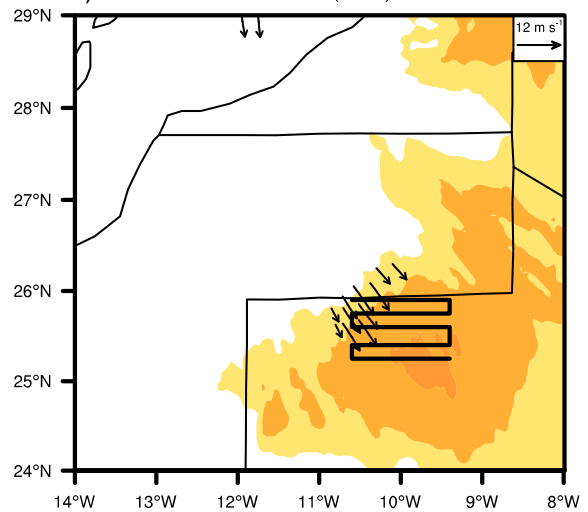

f) 11 June 201112 UTC (t+12) Meso-NH $\Delta x=1 \mathrm{~km}$

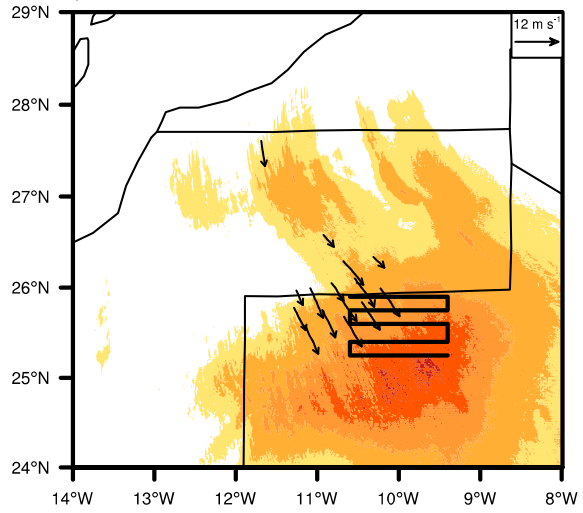

Dust Optical Depth (-)

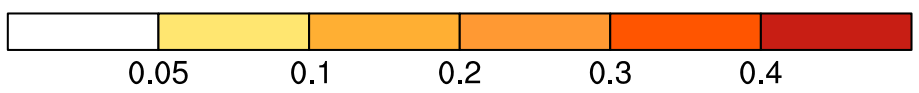

Figure 9. Fields of dust optical depth representing the atmospheric total column dust loading for (a, c, and e) 09 UTC and (b, d, and f) 12 UTC for the two models (a and b) AROME and Meso-NH with a (c and d) $5 \mathrm{~km}$ and (e and f) $1 \mathrm{~km}$ grid spacing. Position of F20 flight track is given by black solid line. Arrows represent the wind at $10 \mathrm{~m}$ stronger than $8 \mathrm{~m} \mathrm{~s}^{-1}$.

orientation. The average depth of valleys and endorheic systems over the domain is typically $10 \mathrm{~m}$ to $30 \mathrm{~m}$. Although not all valleys/drainage systems are represented by above the background level increased dust loading, a predominance is evident. Multiple transects over one valley system, but at different latitudes, may show increasing dust loading not only due to direct dust emission but also due to accumulation caused by downwind transport. The valley system located between $10.2^{\circ} \mathrm{W}$ and $9.8^{\circ} \mathrm{W}$ (Figure 7) consists of three individual valleys at $25.9^{\circ} \mathrm{N}$ ("3a," " $3 \mathrm{~b}$," and " 4 " in Figure 7) merging into one valley at $25.6^{\circ} \mathrm{N}$ (" 34 " in Figure 7). A second dominant valley system that is crossed by several flight legs is located between $9.9^{\circ} \mathrm{W}$ and $9.6^{\circ} \mathrm{W}$. It consists of the valleys numbered as " $5 \mathrm{a}$," " $5 \mathrm{~b}$," " 6 ," and "7". The valleys merge step by step to valley "567" at $25.3^{\circ} \mathrm{N}$. 

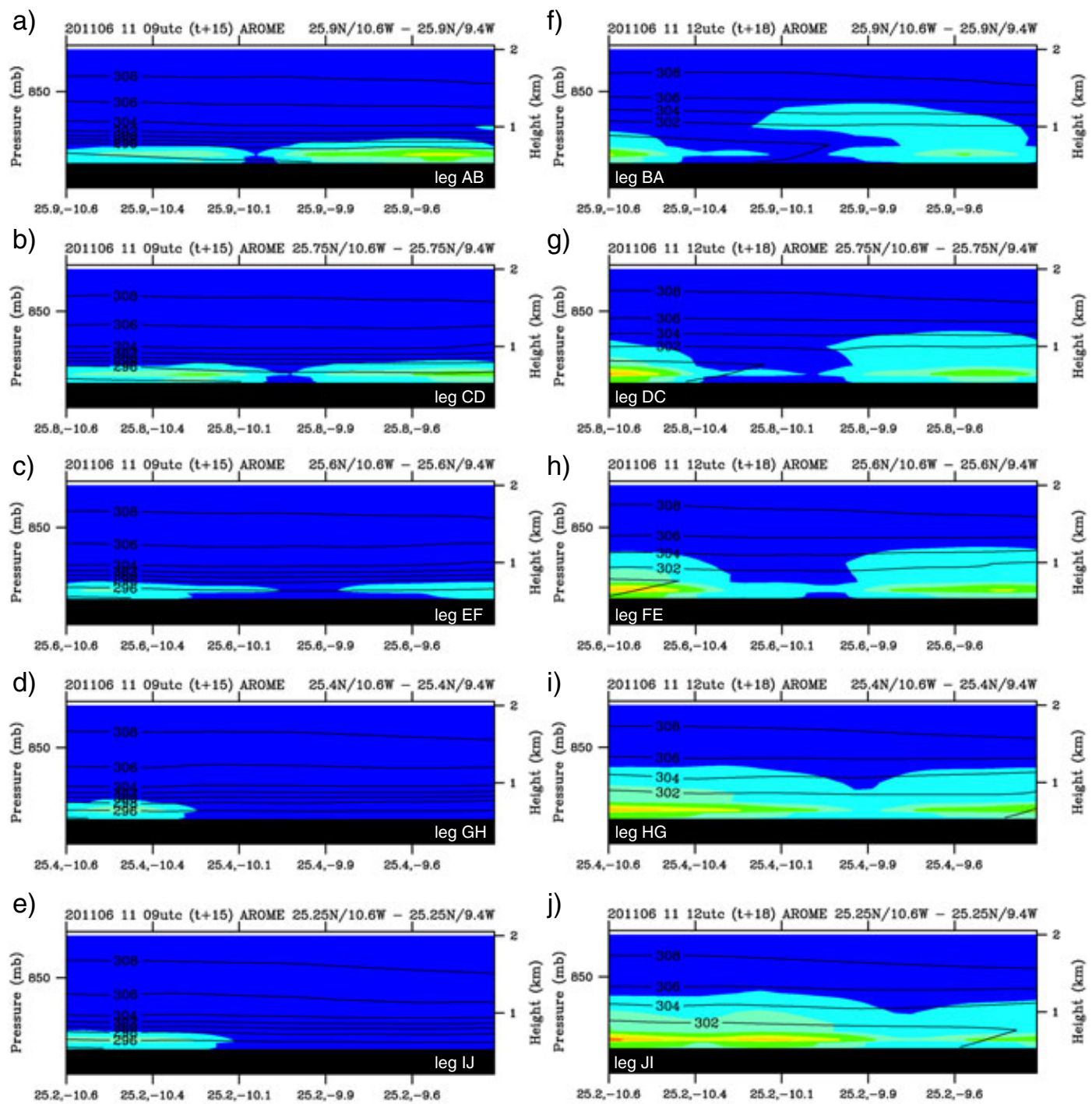

Dust extinction $\left(10^{-6} \mathrm{~m}^{-1}\right)$

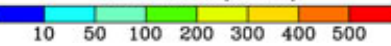

Figure 10. Vertical distribution of extinction coefficient representing the dust concentration simulated by AROME for each leg at (a-e) 09 UTC and $(\mathrm{f}-\mathrm{j}) 12 \mathrm{UTC}$. Potential temperature [K] is given by contour lines.

[46] Vertical profiles of lidar-derived PECs provide information on the altitude of the dust layer. As the measurements were taken over a dust source region, and neither dust plumes from previous days nor advected dust plumes were present, dust concentration is highest within the shallow PBL. Lidar observations during previous and subsequent flights during June 2011 passing over the RAIN4DUST research domain and the adjacent Atlantic region indicate that lowest dust AOD values are observed on 8 June 2011 suggesting that the level of aged dust advected from remote sources into the research domain is low. Also, the atmospheric aerosol loading above the PBL, where dust usually emitted during previous days can be found, is low $\left(<100 \times 10^{-6} \mathrm{~m}^{-1}\right)$. As shown by the comparison between PEC and topography, above background level increased PECs are frequently observed over wide valleys. Figure 8 shows an example comparison of vertical PEC profiles for valley "3" along flight leg CD (Figure 8c). In addition, aerial photographs for the valley and one position over adjacent, higher terrain are given (Figures $8 \mathrm{a}$ and $8 \mathrm{~b}$ ). The profile over the valley center shows high PEC of more than $600 \times 10^{-6} \mathrm{~m}^{-1}$ within the PBL, which leads to an AOD of around 0.6 (Figure $4 \mathrm{~b}$ ). Profiles for two locations over adjacent, higher terrain (peaks) show significantly lower dust concentration within the PBL, represented by PECs of up to $300 \times 10^{-6} \mathrm{~m}^{-1}$ and a corresponding AOD of 0.3 .

[47] Aerosol optical depths calculated from the lidar measurements are further compared to AODs retrieved from MSG SEVIRI observations (Figure 4). As the aircraft measurements were taken during the initial dust emission phase that begins with the breakdown of the nocturnal LLJ during the morning hours, and air above the PBL is rather dust-free due to advection from the Atlantic, AODs calculated from the satellite observations can be assumed to be comparable to AODs retrieved from the airborne lidar observations. Irregularities in AOD that appear in MSG SEVIRI 
a)

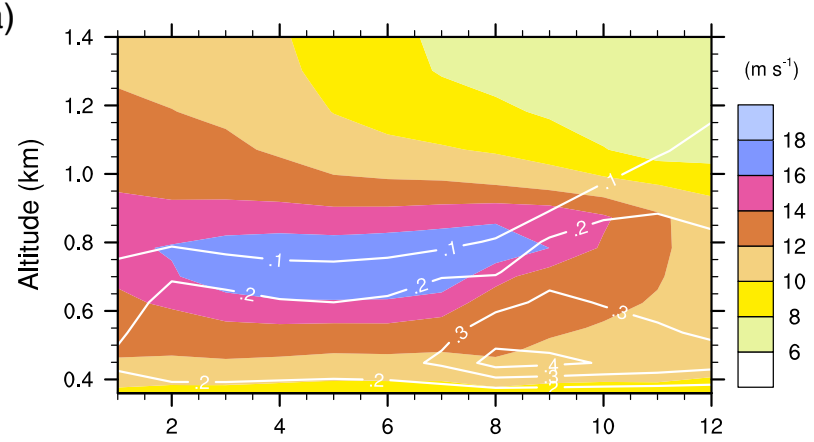

b)

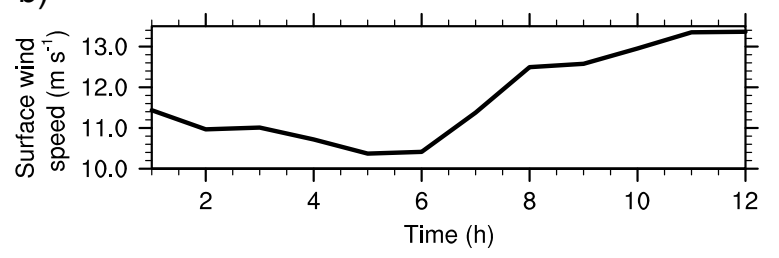

Figure 11. (a) Temporal evolution of the vertical distribution of wind speed (shading, $\mathrm{m} \mathrm{s}^{-1}$ ) and dust extinction (white lines, $10^{-6} \mathrm{~kg} \mathrm{~m}^{-2}$ ) for $5 \mathrm{~km}$ Meso-NH simulation. (b) Temporal evolution of the surface wind speed. Values represent spatial mean over the domain covered by the aircraft.

AOD series may be due to the reference image used for data processing. As described by Brindley and Russell [2009] in detail, a pristine, cloud-free reference field is obtained for a 28 day rolling window. In the presence of dust and with increasing atmospheric dust loading, the surface brightness temperature is decreased relative to the pristine reference case. The reference scene is retrieved for each retrieval time step and pixel individually.

[48] The distribution of MSG SEVIRI AODs as shown in Figure 4 along each flight leg suggests a spatial distribution following the main topographic features, which increased AOD over the main valley centered at $10^{\circ} \mathrm{W}$ (compare also with Figure 1 for an overview on the topography of the domain). SEVIRI AODs are plotted at the native sampling scale of the measurements (approx. $4 \mathrm{~km}$ ). Horizontal variability in AOD occurring at spatial scales less than the instrument resolution would not be captured, and hence, the derived AODs along the flight tracks appear smoother than those obtained from lidar. As dust emission is still in progress during the morning, dust plumes are under development as well. Thus, local dust concentrations may significantly increase during two MSG SEVIRI AOD retrieval time steps leading to "jumping" AODs as evident from Figure 4. Transport of dust becomes a more dominant feature in particular later during the morning.

[49] With respect to the horizontal and temporal resolution, and age of the dust plume, SEVIRI AODs show the tendency to be higher over valleys and lower over summits. For example, for the corresponding 10 UTC time slot, the MSG SEVIRI AOD is increased over the valley at $10^{\circ} \mathrm{W}$ along leg EF. However, a relation between increased dust concentrations and topography at the scale of individual valleys, as was seen for the LNG measurements, cannot be resolved from the SEVIRI AODs because of their relative limited spatial resolution.
[50] The heterogeneity of the terrain and thus its ruggedness is highest over the northwestern part of the domain covered by the flight track and decreases toward the southeastern part of the domain. The complexity of the terrain along the flight track is well documented by aerial photographs taken during the flight. Photographs for two different valley systems that are crossed by each flight leg are shown in Figure 5. The pictures are sorted as follows: the two valley systems are represented by the two columns, whereby pictures taken over the valley initially labeled as " $3 \mathrm{a}$ " on Figure 7 for leg AB/BA are given on the left side, and pictures for the valley system labelled as "5a" for leg AB/BA are shown on the right side. Moreover, the upper part of both valley systems are characterized by narrow and well-defined drainage systems. Over the meridional course of the valley, the bottom floor widens and extensive sandy surfaces appear. Whereas individual flowing channels are clearly identified for leg $\mathrm{AB} / \mathrm{BA}$ to $\mathrm{EF} / \mathrm{FE}$, wide plains characterize the valley bottom, although drainage channels are evident but not as pronounced as upstream.

\section{Model Evaluation}

[51] Two mesoscale models were providing dust and weather forecasts during the Fennec aircraft campaign in June 2011, the operational forecast model AROME and research model Meso-NH. The dust module and physics parametrization of both models are similar, but they differ in their dynamical core. Because of their difference in their dynamical core, the two models differ in the tuning of the sandblasting efficiency (defined as the conversion of the horizontal saltation flux into vertical dust flux). The sandblasting efficiency is an empirical parameter that depends on the dynamics of the meteorological model and therefore requires tuning. This tuning was performed for AROME using observation data from the AMMA campaign for June 2006 as described in Kocha et al. [2011], and for MesoNH using observations provided by AERONET for June 2011. The model-dependent choice of this parameter leads to differences in the relation of wind speed and vertical dust emission flux. In the following, the dust forecast simulations of AROME and the dust simulations of Meso-NH will be compared to the aircraft observations.

[52] A sensitivity test on the impact of the horizontal grid spacing, in particular with regard to the representation of the topography, were performed running Meso-NH additionally with $1 \mathrm{~km}$ grid spacing.

\subsection{AROME}

[53] The calm conditions at surface level and the prevailing northerly wind direction and hence the advection of pristine, maritime air leads to low dust atmospheric column loadings during the night and early morning on 11 June 2011. Between 06 and 09 UTC boundary layer, turbulence increases and dust emission begins. At 09 UTC, small and optically thin dust plumes with AODs of up to 0.1 occur over a region roughly between $11.0-9.0^{\circ} \mathrm{W}$ and $25.5-27.75^{\circ} \mathrm{N}$ (Figure 9a). As dust emission continues, the atmospheric dust loading increases in mass and extent. At 12 UTC, a dust plume with an AOD of up to 0.2 is covering a domain east of $9.75^{\circ} \mathrm{W}$ roughly extending from $25.0^{\circ} \mathrm{N}$ to $27.75^{\circ} \mathrm{N}$ 
a) 11 June 201109 UTC Meso-NH $\Delta x=5 \mathrm{~km}$

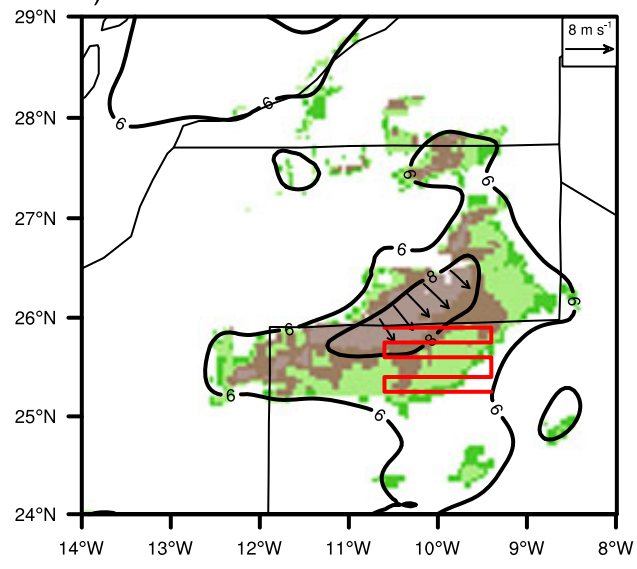

C) 11 June 201109 UTC Meso-NH $\Delta x=1 \mathrm{~km}$

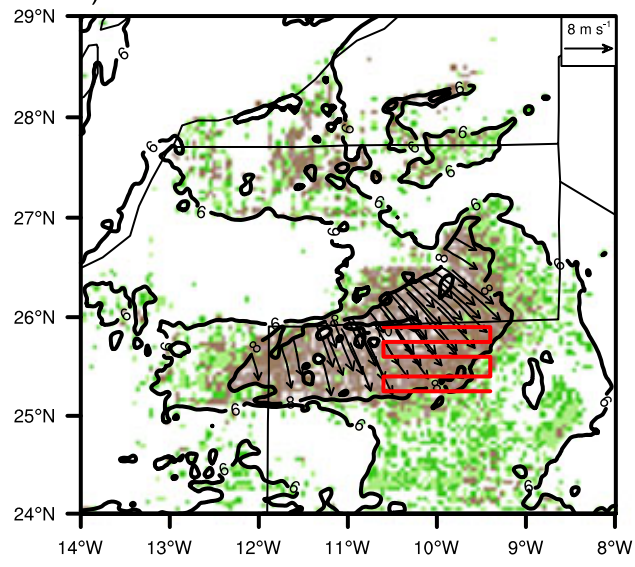

e) 11 June 201109 UTC Meso-NH $\Delta x=5 \mathrm{~km}$

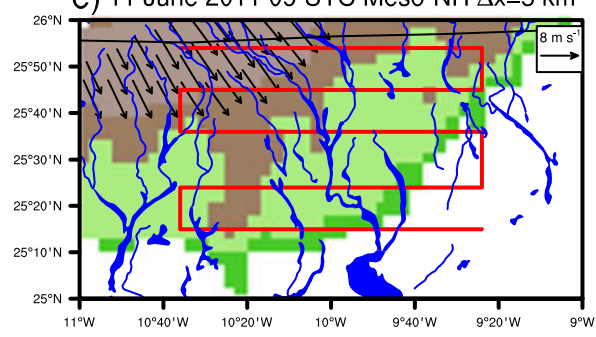

g) 11 June 201109 UTC Meso-NH $\Delta x=1 \mathrm{~km}$

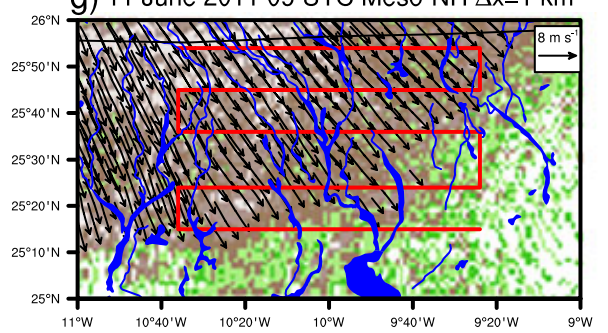

b) 11 June 201112 UTC Meso-NH $\Delta x=5 \mathrm{~km}$

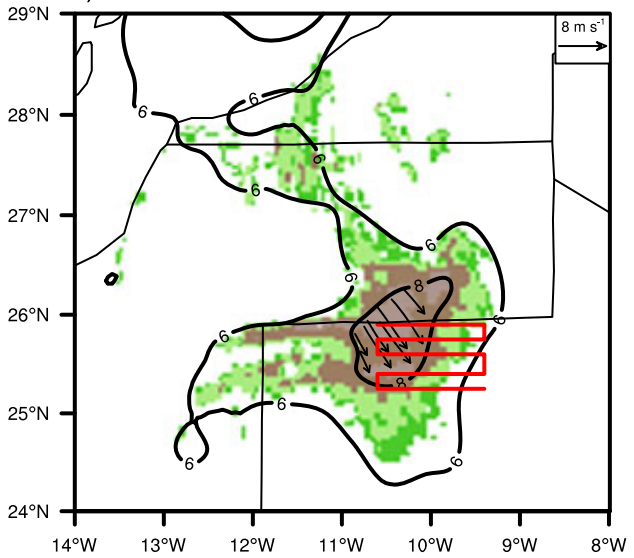

d) 11 June 201112 UTC Meso-NH $\Delta x=1 \mathrm{~km}$

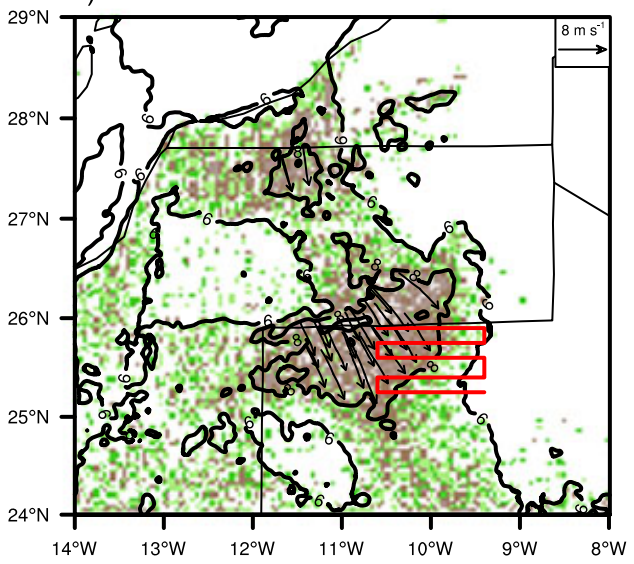

f) 11 June 201112 UTC Meso-NH $\Delta x=5 \mathrm{~km}$

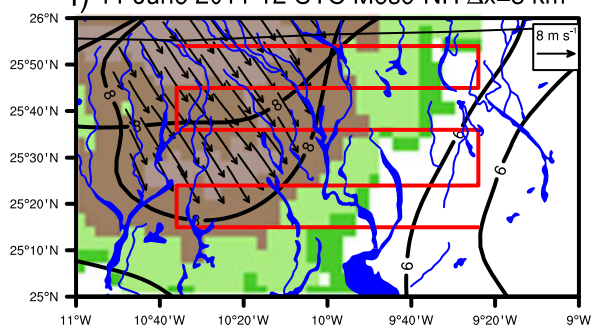

h) 11 June 201112 UTC Meso-NH $\Delta x=1 \mathrm{~km}$

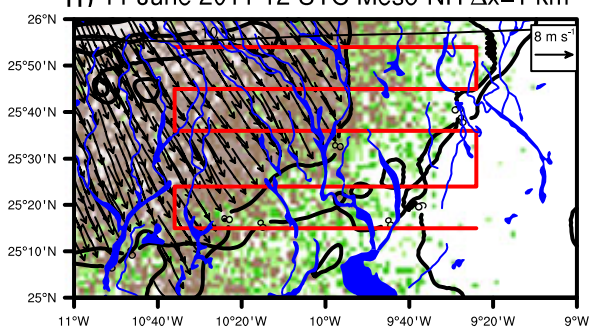

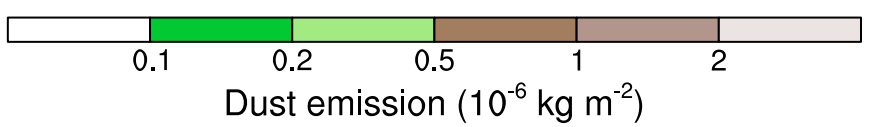

Figure 12. Dust emission (color shading) and $10 \mathrm{~m}$ wind speed (lines at 6 and $8 \mathrm{~m} \mathrm{~s}^{-1}$ and arrow over $8 \mathrm{~m} \mathrm{~s}^{-1}$ ) at (left column) 09 UTC and (right column) 12 UTC for the Meso-NH runs at (a, b, e, and f) 5 $\mathrm{km}$ and (c, d, g, h) $1 \mathrm{~km}$ grid spacing. Position of F20 flight track is given by red solid line. A zoom into the RAIN4DUST research area is given by Figures $12 \mathrm{e}, 12 \mathrm{f}$, and $12 \mathrm{~g}, 12 \mathrm{~h}$ for the $5 \mathrm{~km}$ and $1 \mathrm{~km}$ grid spacings, respectively. Temporal flooded river systems are shaded in blue. 

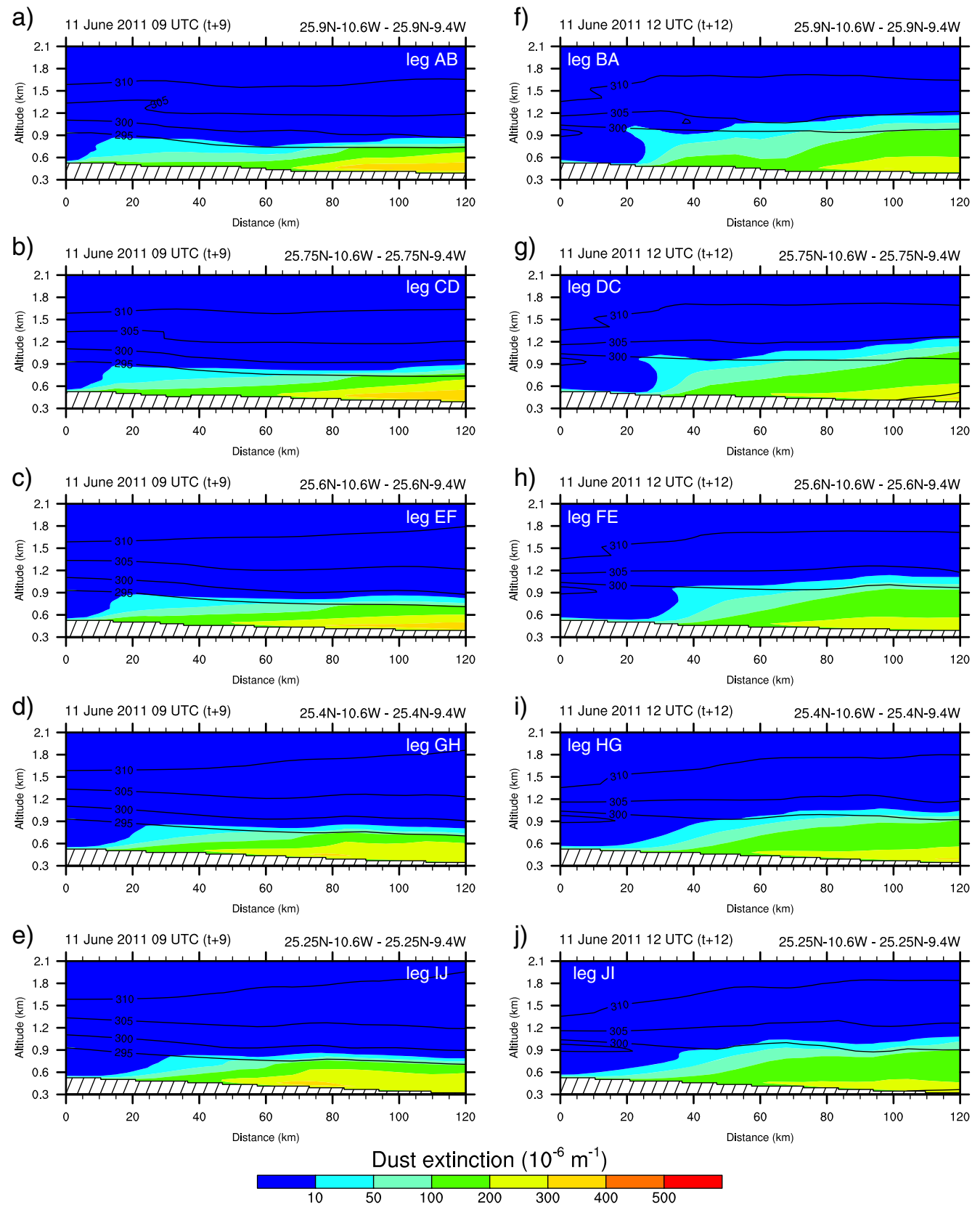

Figure 13. Vertical distribution of extinction coefficient representing the dust concentration simulated by Meso-NH with $5 \mathrm{~km}$ grid spacing for each leg at (a-e) 09 UTC and (f-j) 12 UTC. Potential temperature $[\mathrm{K}]$ is shown by contours.

(Figure 9b). A second, but optical thinner dust plume is covering a region between $11.0-9.75^{\circ} \mathrm{W}$ and $24.5-26.0^{\circ} \mathrm{N}$.

[54] Parts of both dust plumes that develop over north Mauritania are located within the domain that is crossed zonally several times by the F20. The vertical distribution of dust in the form of PEC is shown in Figure 10 for each leg for 09 and 12 UTC. As the aircraft was flying over the domain between 10 and 11:30 UTC, the outbound flight is closer to 09 UTC (Figures 9a-9e) and the return flight closer to 12 UTC (Figures 9f-9j). As also discussed in section 4.2, the PBL develops significantly between 09 and 12 UTC. As the largest fraction of dust aerosol is mixed within the PBL, the top of the PBL is marked by a significant decrease in dust concentration and therefore in PEC. Taking this as an indicator for the top of the PBL, the boundary layer deepens by up to $500 \mathrm{~m}$ during the $3 \mathrm{~h}$. Two regions of increased PEC are evident. One is located over the eastern part of the leg and one over the western part separated by a minimum at around $10.1-10.0^{\circ} \mathrm{W}$ as shown in Figures $10 \mathrm{a}-10 \mathrm{c}$, and Figures $10 \mathrm{f}-10 \mathrm{~h}$ in particular. As dust emission proceeds, and also as regional dust transport occurs, dust concentration increases as represented by an increased PEC. At 09 UTC, the isolines of PEC are situated concentric around the local maxima forming an elliptic semisphere laying on the surface. This is the case for a dust plume caused by immediate, local dust emission. At 12 UTC, dust plumes are already transported downwind and thus the shape of the isolines of PEC is not a concentric, elliptic semisphere anymore. 
a)

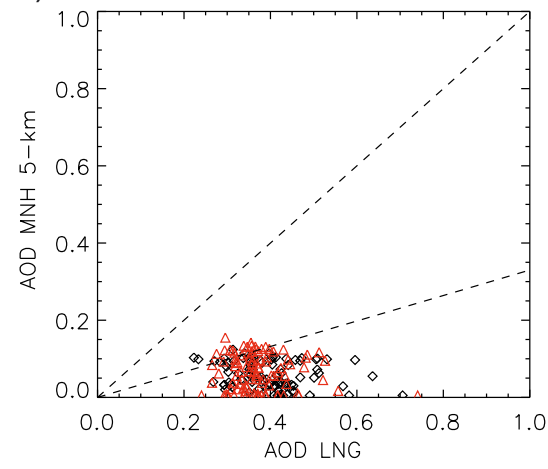

b)

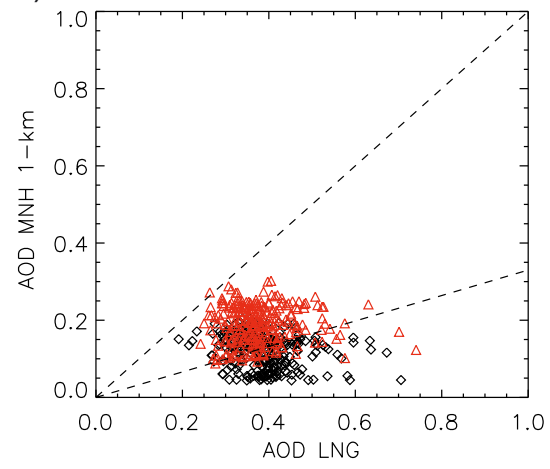

Figure 14. Scatter plot presenting the relation between AODs retrieved from LNG observations and those simulated by Meso-NH along the outbound flight (black diamonds) and the return flight (red triangles). (a) for LNG AOD and Meso-NH AOD at $5 \mathrm{~km}$ horizontal grid spacing, (b) same as Figure 14a, but for $1 \mathrm{~km}$ horizontal grid spacing.

The maximum PEC per layer is elevated and tilted toward the horizontal transport direction as transport is faster at higher levels than at lower due to surface friction. Both dust plumes show evidence for horizontal transport with a predominant zonal component at 12 UTC compared to 09 UTC (Figures $10 \mathrm{f}-10 \mathrm{j}$ ). This is in agreement with the predominant westerly wind direction at $700 \mathrm{hPa}$. The evolution of the dust plume as seen by the model is not evident from the lidar measurements. The lidar measurements suggest high dust concentrations at low levels with maximum dust loading over valleys. A tilt of the vertical axis of dust plumes is not observed. This suggests that not only the location of the dust sources but also the strength of the dust emission fluxes, as indicated by the observations, are seen in a different way by the model.

\subsection{Meso-NH at $5 \mathrm{~km}$ Grid Spacing}

[55] The regional research model Meso-NH is used here not only to compare to the AROME simulation but also to further investigate the model sensitivity to the horizontal resolution.

[56] The general distribution of dust simulated by Meso$\mathrm{NH}$ with a $5 \mathrm{~km}$ grid spacing is similar to that simulated by AROME, but the atmospheric dust optical depths are much higher in Meso-NH fields than in AROME fields (Figure 9). The differently chosen sandblasting efficiency can be assumed as a main reason for the differences in simulated dust loadings as the wind fields follow similar distributions. Meso-NH simulates a dust plume over northeastern Western Sahara and northwestern Mauritania. Dust emission fluxes simulated by Meso-NH are higher than those simulated by AROME. The dust AOD at 09 UTC is up to twice as high (up to 0.2) as in the AROME simulation (up to 0.1), but four times as high at 12 UTC. Additionally, compared to AROME, dust emission is also simulated during the night, and higher dust concentrations accumulate with time. Overall, the dust emission flux shows a minimum between 05 and 06 UTC (Figure 11) and increases significantly onward. As shown in Figure 11a, the low-level wind maximum (up to $18 \mathrm{~m} \mathrm{~s}^{-1}$ ) develops during the night reaching its maximum in wind speed and vertical extent at 06 UTC. After sunrise at 05:49 UTC, solar heating sets on, and convective turbulence increases. With increasing tur- bulence, the nocturnal temperature inversion separating the NBL from the LLJ embedded in the residual BL is eroded. The residual layer couples to the surface layer, and momentum from the LLJ is mixed downward. The average surface wind speed increases by more than $2 \mathrm{~m} \mathrm{~s}^{-1}$ during 6 to 8 UTC (Figure 11b). At $11 \mathrm{UTC}$, the PBL is characterized by a constant vertical wind profile indicating that the momentum from the LLJ is mixed over the entire PBL, and the average surface wind speeds remains at a constant level. With increasing surface wind speeds after 06 UTC, the dust emission flux increases accordingly. With increasing convective turbulence, dust is mixed upward into the PBL (Figure 11). Due to the prevailing northerly wind direction and dust emission occurring further upwind the area covered by the flight legs, dust advected into the domain is contributing to the dust concentration (Figures 9 and 12). Once the momentum from the LLJ layer is mixed over the entire PBL, surface wind speeds decrease and with it the dust emission flux. Thus, the vertical gradient in dust extinction decreases as well.

[57] The main dust source region, for which significant dust emission fluxes are simulated, is the mountain area in the border region of Western Sahara and north Mauritania (Seguiet El Hamra region) (Figures 12a and 12b). Dust emission fluxes are up to $2 \times 10^{-6} \mathrm{~kg} \mathrm{~m}^{-2}$ and are highest at 09 UTC over the Mauritanian border region between $11.5^{\circ} \mathrm{W}$ and $10.0^{\circ} \mathrm{W}$.

[58] The dust emission fluxes show a zonal gradient with values of $8-10 \times 10^{-6} \mathrm{~kg} \mathrm{~m}^{-2}$ over the western part of the flight tracks and lower fluxes of $6-8 \times 10^{-6} \mathrm{~kg} \mathrm{~m}^{-2}$ over the eastern part of the flight tracks. The comparison with horizontal wind speed distribution identifies the wind speed as controlling factor for the horizontal variability of dust emission fluxes as soil texture characteristics are constant over the whole domain.

[59] However, dust AODs simulated by Meso-NH are higher over the eastern part of the flight tracks than over the western part (Figure 9). As shown in Figures 9 and 12, dust emitted over the western part is transported eastward, mainly within the boundary layer, as dust extinction is very low and constant above the PBL (Figure 13).

[60] Vertical dust concentrations along the flight tracks lead to high PECs within the first layers within the PBL. At 09 UTC, a sharp decrease in dust concentration marks the top 

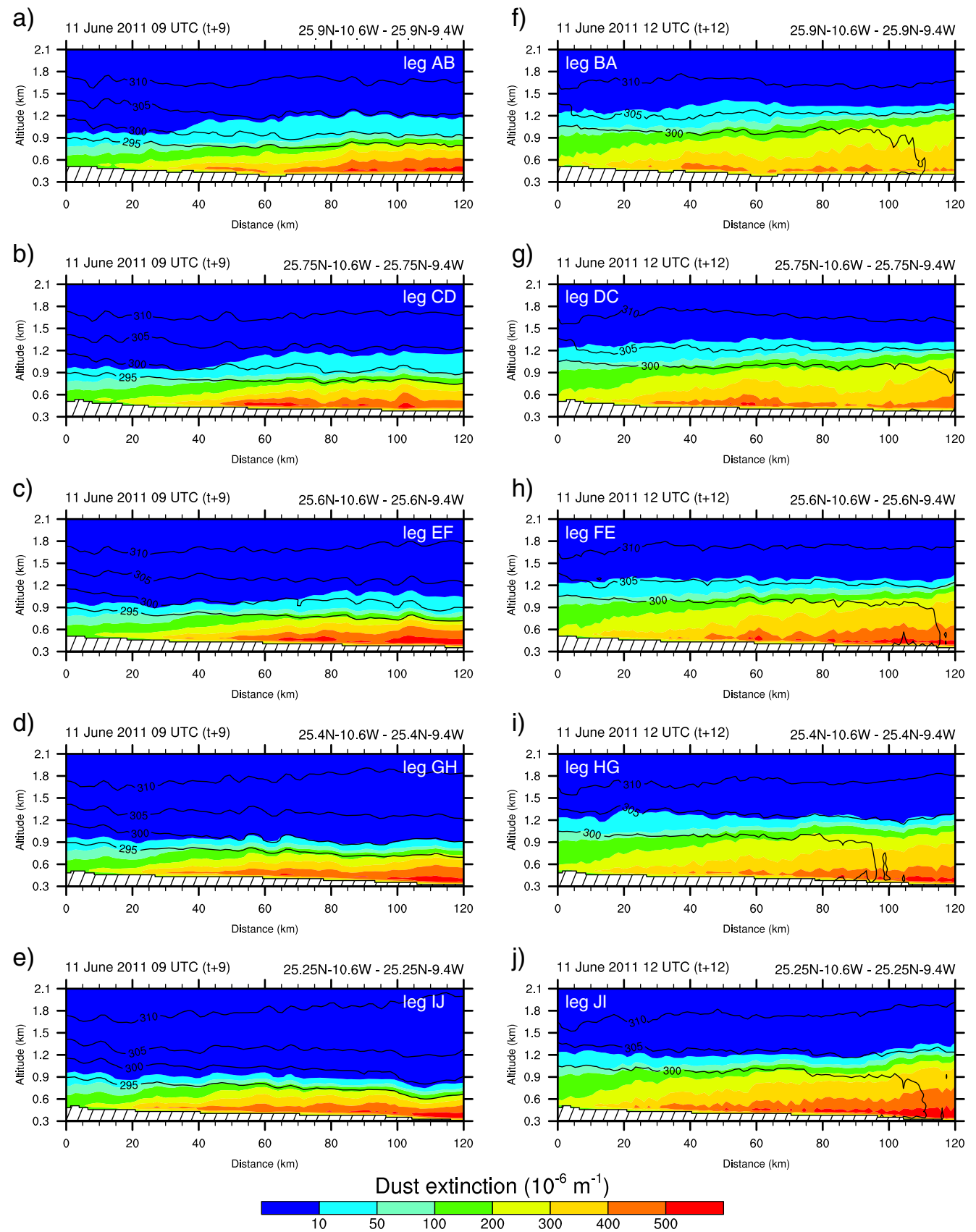

Figure 15. Vertical distribution of extinction coefficient representing the dust concentration simulated by Meso-NH with $1 \mathrm{~km}$ grid spacing for each leg at (a-e) 09 UTC and (f-j) 12 UTC. Potential temperature $[\mathrm{K}]$ is shown by contours.

of the PBL at 300-500 $\mathrm{m}$ agl. The top of the PBL decreases along the flight track toward the west with increasing terrain heterogeneity. Compared to the depth of the PBL indicated by the dropsonde observations and vertical PEC distribution retrieved from the lidar observation, the simulated depth of the PBL is about 200-300 m shallower. Dust PECs with up to $400 \times 10^{-6} \mathrm{~m}^{-1}$ are simulated over the eastern part of the flight legs, where the model topography is shallower (Figure 13). The background dustiness is characterized by a dust PEC of $300-400 \times 10^{-6} \mathrm{~m}^{-1}$. The simulated background dust extinction and local maxima are in the range of extinctions retrieved from lidar observations. The observations, however, indicate these values for a much deeper layer. Consequently, the simulated vertical column dust concentration is lower than observed, which is also indicated by the lower than observed dust AOD values. Figure 14a illustrates the relation between the AOD retrieved from $\mathrm{LNG}$ observations and the simulated AODs separately for the outbound (diamonds) and the return (triangles) flight. During both parts of the flight, the $5 \mathrm{~km}$ grid spacing simulated AOD is lower than the AOD indicated by the lidar observations. No significant change for the relation between the outbound and the return flight is evident, which is also suggested by the AOD distribution shown in Figures 9c and 9d. 
[61] At 12 UTC, the background dustiness has decreased and is represented by a dust PEC of $200-300 \times 10^{-6} \mathrm{~m}^{-1}$, which is still slightly lower than the observed background PEC of $300-400 \times 10^{-6} \mathrm{~m}^{-1}$ (Figure 4). The PBL has deepened to up to $1000 \mathrm{~m}$ agl, but is still shallower than observed. Compared to 09 UTC, the dust PECs along the flight tracks are more variable, but local hot spots in PECs in the surface layer are less pronounced.

[62] The relation between the horizontal distribution of PECs and topography, in particular increased PECs over valleys, cannot be concluded from the $5 \mathrm{~km}$ model simulations. In contrast to the observed PECs (Figure 4), the simulated dust extinctions show only little horizontal variability. Overall, the zonal distribution is dominated by dust concentrations increasing from west to east, which is also represented by the horizontal AOD distribution as shown in Figure 9, but not observed. The simulated distribution pattern is more likely due to effects of topography on transport and post-emission accumulation than due to local dust emission within the valley. As soil texture is constant over the whole domain, and no preferential dust sources are prescribed, alluvial sources are not represented explicitly, and wind speed is the determining factor for dust emission. Furthermore, the spatial comparison of dust emission fluxes and the location of endorheic systems (Figures 12e-12h) does not suggest an increased dust emission flux from desert valleys. Due to increased PBL turbulence and dust transport, the horizontal dust distribution is more uniform at 12 UTC than at 09 UTC.

\subsection{Meso-NH at $1 \mathbf{~ k m}$ Grid Spacing}

[63] To further examine the impact of the horizontal resolution on the simulation of dust emission, a Meso-NH run with $1 \mathrm{~km}$ grid spacing was performed. The complexity of the topography especially over the northern part of the RAIN4DUST research domain is better represented at $1 \mathrm{~km}$ grid spacing than at $5 \mathrm{~km}$. The horizontal variability of near-surface winds is higher, as well as the wind speed. Furthermore, surface heterogeneity that affects surface heating and cooling and therefore the sensitivity of turbulence elements within the PBL contributes to an increased spatial variability in surface wind speeds in terms of its standard deviation over the domain.

[64] The simulated $10 \mathrm{~m}$ wind speeds are higher (Figures 12c and 12d) than for the $5 \mathrm{~km}$ run (Figures 12a and $12 \mathrm{~b}$ ), but the general pattern distribution remains similar. Local dust emission fluxes are increased for the 1 $\mathrm{km}$ simulation accordingly, although the dust source areas remain (Figures 12c and 12d). Due to increased dust emission fluxes, the horizontal distribution of dust plumes as represented by the dust AOD (Figures 9e and 9f) shows increased values of up to 0.5 for the $1 \mathrm{~km}$ simulation. The pattern of dust AOD distribution is similar to the $5 \mathrm{~km}$ run, although dust plumes originating from dust emission over the Morocco-Western Sahara border region are more pronounced in the $1 \mathrm{~km}$ simulations. The observed maximum AOD is close to maximum values retrieved from the lidar PECs. Although the simulated AOD values are still lower than observed AODs (Figure 14b), the level of dustiness is increased compared to the $5 \mathrm{~km}$ Meso-NH simulation. Furthermore, the relation between observed and simulated AOD is changing with time as evident when considering the out- bound and return flight separately. Also, Figures 9e and $9 \mathrm{f}$ suggest an increase in AOD during the flight over the domain of interest.

[65] The vertical distribution of PEC as shown in Figure 15 suggests similar PBL heights and temporal development for the $1 \mathrm{~km}$ simulation as well as for the $5 \mathrm{~km}$ simulation. Topographic heterogeneity higher affects the thermodynamics of the PBL. Thus, an enhanced spatial variability in dust extinction is evident. Due to the higher dust emission fluxes, dust extinction within the PBL and in particular within the lowest layers are higher $\left(>400 \times 10^{-6} \mathrm{~m}^{-1}\right)$. Also, the spatial variability in dust PEC is higher in the $1 \mathrm{~km}$ simulation.

[66] Similar to the $5 \mathrm{~km}$ simulation, the dust extinction and AOD along the flight tracks increases zonally from west to east. Assuming that observed dust plumes represent local dust emission, the spatial distribution of the simulated dust emission fluxes compare well with the observations.

\section{Discussion}

[67] The distribution of dust over the research domain is highly affected by the synoptic situation. As the Atlantic is about $200-300 \mathrm{~km}$ upwind, the northerly advection of maritime air limits the transport of dusty air from the Sahara into the domain. Hence, simulated dust emission is local, and dust plumes are only transported within the regional scale. Both models simulate the advection of maritime air into the continent in the vicinity of the Azores high well (section 4.1), although differences in local boundary layer depth occur. Following the wind speed distribution, dust emission is simulated over the region by both models, although spatial and temporal difference in dust emission fluxes are evident. Compared to the lidar and MSG SEVIRI AOD observations, however, both models underestimate the atmospheric dust loading. As the models consist of the same dust emission module and physical parametrization, but have different description of the atmospheric dynamics (cf. section 3), different vertical resolutions, and different saltation mass efficiencies (cf. section 3.5.4), differences not only in dust loadings but also in horizontal and vertical distributions are expected.

[68] The dust extinction simulated by Meso-NH at $5 \mathrm{~km}$ grid spacing shows a zonal gradient that is opposite of the observed. The distribution of dust emission fluxes shows higher values over the western part than over the eastern part, whereas the airborne lidar measurements and MSG SEVIRI AOD retrievals suggest higher dust emission fluxes and thus higher AODs over areas where the topography is characterized by rugged terrain. Thus, it can be concluded that the higher simulated dust concentration over the east is mainly caused by dust transport. Consequently, neglecting dust transport, dust concentrations would be higher over the western part of the legs, in accordance with the observations. This suggests that simulated dust transport in easterly direction is too strong. The reason for this may be the smoothed topography where steeper valleys (here orientated in meridional direction) would provide natural barriers for eastward (zonal) dust transport. Additionally, the soil texture as a determining factor for simulating dust emission besides the wind speed, does not vary spatially over the domain. Thus, the spatial variability in dust emission fluxes is mainly con- 
trolled by the spatial variability in wind speed, which is affected by the topography.

[69] Compared to the $5 \mathrm{~km}$ Meso-NH simulation, the $1 \mathrm{~km}$ Meso-NH simulation shows increased surface wind speeds and thus increased dust emission fluxes. The increased horizontal and vertical resolution is likely to be the main reason for increased wind speeds as this affects atmospheric stability and turbulence and thus the development and decay of the nocturnal LLJ. The maximum of the computed dust AOD compares well with the maximum AOD retrieved from lidar PECs. Furthermore, the $1 \mathrm{~km}$ simulation shows an increased horizontal variability in dust emission fluxes, as well as consistently in $10 \mathrm{~m}$ wind speeds.

[70] Although model simulations by AROME and Meso$\mathrm{NH}$ at $5 \mathrm{~km}$ grid spacing show dust emission over the research domain, the variability in dust concentration as obtained from airborne remote sensing measurements is not represented. This is mainly due to the fact that the soil properties used by the dust emission module do not explicitly represent alluvial sources, which can be assumed to be the dominant source type over the research domain. The soil texture fields used as input field indicated constant sand, silt, and clay distributions for the entire RAIN4DUST domain. Thus, no heterogeneity in soil text distribution as suggested by the aerial photographs is prescribed to the dust emission model. Horizontal variability in dust emission is solely controlled by the horizontal wind speed distribution.

[71] The work by Koven and Fung [2008] studying the importance of different land forms as dust source in a high-resolution modeling frame illustrates the importance of low-slope environments like alluvial sediments as a predominant dust source due to the abundance of fine sediments that are prone to wind erosion. Their results further underline the importance to closer study dust emission from this source type.

[72] A recent sensitivity study by Mohktari et al. [2012] has shown that an improved representation soil size distributions helps to better represent the spatial variability of dust emission fluxes. In particular, surface dust concentrations over the Bodélé Depression have been improved by using the revised DEAD module. This new parametrization may also help to improve the representation of dust emission fluxes from alluvial sources.

\section{Conclusion}

[73] The airborne lidar measurements of extinction coefficients providing the vertical column distribution of aerosols (here mainly dust) show a complex horizontal distribution of dust concentrations. The comparison of horizontal variability of PEC values along the flight tracks with surface topography suggests an increase in PBL dustiness over valleys. Desert valleys are suitable dust source regions as alluvial sediments on the floor of the valleys and drainage systems are very prone to wind erosion. This is also suggested by dust monitoring stations [Reheis and Kihl, 1995] and analysis of satellite data [e.g., Schepanski et al., 2007, 2009, 2012a; Bullard et al., 2011; Ginoux et al., 2012].

[74] AROME and Meso-NH model runs at $5 \mathrm{~km}$ horizontal grid spacing show a general dustiness over the study area in north West Africa, but fail to represent the horizontal distribution of dust concentration variations within the
PBL as observed by airborne measurements or as indicated by MSG SEVIRI AOD retrievals. A comparison of dust emission fluxes with observed PECs and also SEVIRI AOD retrievals shows, however, a good agreement. This suggests that dust transport dominated the horizontal dust distribution, which impedes the analysis of a colocation of dust extinction hot spots and valleys. Generally, the simulated dust concentrations are lower than observed.

[75] The Meso-NH simulation at $1 \mathrm{~km}$ grid spacing shows dust concentrations similar to the observed concentrations. The spatial variability in dust emission fluxes is increased, in particular, over regions with increased terrain ruggedness over the western part of the flight tracks. As for the $5 \mathrm{~km}$ simulation, the spatial distribution of the dust emission flux compares well with the distribution of observed PECs, but dust transport leads to higher dust AODs over the eastern part of the flight tracks.

[76] The analysis of the airborne measurements points toward a relation between the horizontal distribution of dust concentration and topography. The results suggest that the representation of topography in relation to alluvial dust source is crucial for the simulation of local atmospheric dust loadings. By reducing the grid spacing from $5 \mathrm{~km}$ to $1 \mathrm{~km}$, the representation of atmospheric dust loading was generally improved. Also, the spatial variability in local dust emission fluxes over rugged terrain was increased. However, a relation between dust emission and the location of alluvial sediments cannot be drawn from the model simulations as the soil texture in the model is constant over the entire RAIN4DUST domain and alluvial sources are not represented explicitly. Thus, wind is the determining factor for the horizontal distribution of dust emission fluxes in the model set up used here. Nevertheless, the simulations suggest that horizontal dust transport across valleys may impede our ability to isolate the true impact of local emission from these valleys on the overall dust burden.

[77] These results illustrate the importance of developing an explicit representation of endorheic systems in terms of their role as dust sources in order to better capture the distribution of local dust concentrations.

[78] Acknowledgments. K. Schepanski thanks the Transnational Access program by EUFAR for granting 10 flight hours aboard the F20 operated by SAFIRE in the frame of the RAIN4DUST project. Many thanks to the Fennec team and the SAFIRE team and, in particular F., Pouvesle for support with the ground camera. The authors thank Météo-France and, in particular, J.-P. Lafore, M. Moktari, F. Favot, and F. Beucher for their help to run AROME in real time. The authors are grateful to D. Bruneau and P. Genau (LATMOS), F. Blouzon and A. Abchiche (DT/INSU) for operating the LNG system aboard the F20 and M. E. Brooks (UK Metoffice) for discussion on the manuscript. We thank the ECMWF for providing ERAInterim reanalysis fields. K. Schepanski acknowledged funding from the European Research Council Grant 257543 "Desert Storms". The authors thank three anonymous reviewers for their helpful comments.

\section{References}

Alfaro, S. C., and L. Gomes (2001), Modeling mineral aerosol production by wind erosion: Emission intensities and aerosol size distributions in source areas, J. Geophys. Res., 106(D16), 18,075-18,084.

Ansmann, A., A. Petzold, K. Kandler, I. Tegen, M. Wendisch, D. Müller, B. Weinzierl, T. Müller, and J. Heintzenberg (2011), Saharan mineral dust experiments SAMUM-1 and SAMUM-2: What have we learned?, Tellus, Ser. B, 63(4), 403-429, doi:10.1111/j.1600-0889.2011.00555.X.

Aouizerat, B., O. Thouron, P. Tulet, M. Mallet, L. Gomes, and J. S. Henzing (2010), Development of an online radiative module for the computation of aerosol optical properties in 3-D atmospheric models: 
Validation during the EUCAARI campaign, Geosci. Model Dev, 3 , 553-564, doi:10.5194/GMD-3-553-2010.

Bagnold, R. A. (1941), The Physics of Blown Sand and Desert Dunes, 265 pp., Methuen, New York.

Bangert, M., A. Nenes, B. Vogel, H. Vogel, D. Barahona, V. A. Karydis, P. Kumar, C. Kottmeier, and U. Blahak (2012), Saharan dust event impacts on cloud formation and radiation over Western Europe, Atmos. Chem. Phys., 12, 4045-4063, doi:10.5194/ACP-12-4045-2012.

Banks, J. R., and H. E. Brindley (2013), Evaluation of MSG-SEVIRI mineral dust retrieval products over North Africa and the Middle East, Remote Sens. Environ., 128, 58-73, doi:10.1016/J.RSE.2012.07.017.

Bodhaine, B. A., N. B. Wood, E. G. Dutton, and J. R. Slusser (1999), On Rayleigh optical depth calculations, J. Atmos. Oceanic Technol., 16(11), 1854-1861.

Brindley, H. E., and J. E. Russell (2009), An assessment of Saharan dust loading and the corresponding cloud-free longwave direct radiative effect from geostationary satellite observations, J. Geophys. Res., 114, D23201, doi:10.1029/2008JD011635.

Bullard, J. E., S. P. Harrison, M. C. Baddock, N. Drake, T. E. Gill, G McTainsh, and Y. Sun (2011), Preferential dust sources: A geomorphological classification designed for use in global dust-cycle models, $J$. Geophys. Res., 116, F04034, doi:10.1029/2011JF002061.

Chaboureau, J.-P., E. Richard, J.-P. Pinty, C. Flamant, P. Di Girolamo, C. Kiemle, A. Behrendt, H. Chepfer, M. Chiriaco, and V. Wulfmeyer (2011), Long-range transport of Saharan dust and its radiative impact on precipitation forecast over western Europe: A case study during the Convective and Orographically induced Precipitation Study (COPS), Q. J.R Meteorol. Soc., 137, 236-251, doi:10.1002/QJ.719.

Courtier, P., J.-N. Thépaut, and A. Hollingsworth (1994), A strategy for operational implementation of 4D-Var, using an incremental approach, Q.J. R. Meteorol. Soc., 120, 1367-1387.

Crumeyrolle, S., P. Tulet, L. Gomes, L. Garcia-Carreras, C. Flamant, D. J. Parker, A. Matsuki, P. Formenti, and A. Schwarzenboeck (2011), Transport of dust particles from the Bodele region to the monsoon layer-AMMA case study of the 9-14 June 2006 period, Atmos. Chem. Phys., 11 (2), 479-494, doi:10.5194/ACP-11-479-2011.

Cuesta, J., et al. (2008), Multiplatform observations of the seasonal evolution of the Saharan atmospheric boundary layer in Tamanrasset, Algeria in the framework of the African Monsoon Multidisciplinary Analysis field campaign conducted in 2006, J. Geophys. Res., 113, D00C07, doi:10.1029/2007JD009417.

Dee, D. P., et al. (2011), The ERA-Interim reanalysis: Configuration and performance of the data assimilation system, Q. J. R. Meteorol. Soc., 137 , 553-597, doi:10.1002/QJ.828

DeMott, P. J., K. Sassen, M. R. Poellot, D. Baumgardner, D. C. Rogers, S. D. Brooks, A. J. Prenni, and S. M. Kreidenweis (2003), African dust aerosols as atmospheric cloud ice nuclei, Geophys. Res. Lett., 30(14), 1732, doi:10.1029/2003GL017410

Dubovik, O., B. Holben, T. F. Eck, A. Smirnov, Y. J. Kaufman, M. D. King, D. Tanre, and I. Slutsker (2002), Variability of absorption and optical properties of key aerosol types observed in worldwide locations, $J$. Atmos. Sci., 59(3), 590-608.

Fécan, F., B. Marticorena, and G. Bergametti (1999), Parametrization of the increase of the aeolian erosion threshold wind friction velocity due to soil moisture for arid and semi-arid areas, Ann. Geophys., 17, 149-157.

Fernald, F. G., B. M. Herman, and J. A. Reagan (1972), Determination of aerosol height distributions by lidar, J. Atmos. Meteorol, 11(3), 482-489.

Formenti, P., L. Schütz, Y. Balkanski, K. Desboefs, M. Ebert, K. Kandler, A. Petzold, D. Scheuvens, S. Weinbruch, and D. Zhang (2011), Recent progress in understanding physical and chemical properties of African and Asian mineral dust, Atmos. Chem. Phys., 11, 8231-8256, doi:10.5194/ACP-11-8231-2011.

Foster, P., et al. (2007), Climate Change 2007: The Physical Science Basis, Contribution of Working Group I to the Fourth Assessment Report of Intergovernmental Panel on Climate Change, edited by S. Solomon et al., 996 pp., Cambridge Univ. Press, New York.

Fung, I., S. Meyn, I. Tegen, S. C. Doney, J. John, and J. K. B. Bishop (2000), Iron supply and demand in the upper ocean, Global Biogeochem. Cycles, $14,281-296$

Gillette, D. A., J Adams, A. Endo, D Smith, and R. Kihl (1980), Threshold velocities for input of soil particles into the air by desert soils, J. Geophys. Res., 85, 5621-5630.

Ginoux, P., J. M. Prospero, T. E. Gill, N. C. Hsu, and M. Zhao (2012), Global-scale attribution of anthropogenic and natural dust sources and their emission rates based on MODIS Deep Blue aerosol products, Rev Geophys., 50, RG3005, doi:10.1029/2012RG000388.

Grini, A., P. Tulet, and L. Gomes (2006), Dusty weather forecasts using the Meso-NH mesoscale atmospheric model, J. Geophys. Res., 111, D19205, doi:10.1029/2005JD007007.
Heintzenberg, J. (2009), The SAMUM-1 experiment over Southern Morocco: Overview and introduction, Tellus, Ser. B, 61, 2-11, doi:10.1111/j.1600-0889.2008.00403.X.

Hoose, C., U. Lohmann, R. Erdin, and I. Tegen (2008), The global influence of dust mineralogical composition on heterogeneous ice nucleation in mixed-phase clouds, Environ. Res. Lett., 3(2), 025003, doi:10.1088/17489326/3/2/025003

Huffman, G. J., R. F. Adler, D. T. Bolvin, G. Gu, E. J. Nelkin, K. P. Bowman, Y. Hong, E. F. Stocker, and D. B. Wolff (2007), The TRMM multi-satellite precipitation analysis: Quasi-global, multi-year, combined-sensor precipitation estimates at fine scale, J. Hydrometeorol. $8,38-55$.

Jickells, T. D., et al. (2005), Global iron connections between desert dust, ocean biogeochemistry, and climate, Science, 308(5718), 67-71.

Kocha, C., J. P. Lafore, P. Tulet, and Y. Seity (2011), High-resolution simulation of a major West African dust-storm: Comparison with observations and investigation of dust impact, $Q$. J. R. Meteorol. Soc., 138(663), 455-470, doi:10.1002/QJ.927.

Kok, J. F. (2011), A scaling theory for the size distribution of emitted dust aerosols suggests climate models underestimate the size of the global dust cycle, Proc. Natl. Acad. Sci. U. S. A., 108(3), 1016-1021, doi:10.1073/PNAS.1014798108

Koven, C. D., and I. Fung (2008), Identifying global dust source areas using high-resolution land surface form, J. Geophys. Res., 113, D22204, doi:10.1029/2008JD010195.

Lafore, J.-P., et al. (1998), The Meso-NH atmospheric simulation system. Part I: Adiabatic formulation and control simulations. Scientific objectives and experimental design, Ann. Geophys., 16, 90-109.

Lenschow, D. H., and B. B. Stankov (1979), The rapid morning boundarylayer transition, J. Atmos. Sci., 36, 2108-2124.

Lohmann, U. (2002), Possible aerosol effects on ice clouds via contact nucleation, J. Atmos. Sci., 59, 647-656.

Mahowald, N. M., A. R. Baker, G. Bergametti, N. Brooks, R. A. Duce, T. D. Jickells, N. Kubilay, J. M. Prospero, and I. Tegen (2005), Atmospheric global dust cycle and iron inputs to the ocean, Global Biogeochem. Cycles, 19, GB4025, doi:10.1029/2004GB002402.

Marticorena, B., and G. Bergametti (1995), Modeling the atmospheric dust cycle: 1. Design of a soil-derived dust emission scheme, J. Geophys. Res., 100 (D8), 16,415-16,430.

Masson, V., J. L. Champeaux, F. Chauvin, C. Meriguet, and R. Lacaze (2003), A global database of land surface parameters at 1-km resolution in meteorological and climate models, J. Clim., 16(9), 1261-1282, doi:10.1175/1520-0442-16.9.1261.

Mohktari, M., L. Gomes, P. Tulet, and T. Rezoug (2012), Importance of the surface size distribution of erodible material: An improvement of the Dust Entrainment And Deposition (DEAD) Model, Geosci. Model Dev., 5, 581-598, doi:10.5194/GMD-5-581-2012.

Niedermeier, N., et al. (2012), Mass deposition flux of Saharan mineral dust to the tropical northeast Atlantic Ocean: An intercomparison of methods, Atmos. Chem. Phys. Discuss., 12, 33025-33081, doi:10.5194/ACPD-12$33025-2012$.

Noilhan, J., and J. F. Mahfouf (1996), The ISBA land surface parameterisation scheme, Global Planet. Change, 13(1-4), 145-159, doi:10.1016/0921-8181(95)00043-7.

Prospero, J. M., P. Ginoux, O. Torres, S. E. Nicholson, and T. E. Gill (2002), Environmental characterization of global sources of atmospheric soil dust identified with the NIMBUS 7 Total Ozone Mapping Spectrometer (TOMS) absorbing aerosol product, Rev. Geophys., 40(1), 1002, doi:10.1029/2000RG000095.

Reheis, M. C., and R. Kihl (1995), Dust deposition in Southern Nevada and California, 1984-1989: Relations to climate, source area, and source lithology, J. Geophys. Res., 100(D5), 8893-8918.

Rosenfeld, D., Y. Rudich, and R. Lahav (2001), Desert dust suppressing precipitation: A possible desertification feedback loop, Proc. Natl. Acad. Sci. U. S. A., 98(11), 5975-5980.

Sarthou, G., A. R. Baker, J. Kramer, P. Laan, A. Laes, S. Ussher, E. P. Achterberg, J. H. W. de Baar, K. R. Timmermanns, and S. Blain (2003), Influence of atmospheric inputs on the iron distribution in the subtropical North-East Atlantic Ocean, Mar. Chem., 104, 186-202, doi:10.106/J.MARCHEM.2006.11.004.

Schepanski, K., I. Tegen, B. Laurent, B. Heinold, and A. Macke (2007), A new Saharan dust source activation frequency map derived from MSG-SEVIRI IR-channels, Geophys. Res. Lett., 34, 18803, doi:10.1029/2007GL030168

Schepanski, K., I. Tegen, M. C. Todd, B. Heinold, G. Bönisch, B. Laurent, and A. Macke (2009), Meteorological processes forcing Saharan dust emission inferred from MSG-SEVIRI observations of subdaily source activation and numerical models, J. Geophys. Res., 114, D10201, doi:10.1029/2008JD010325. 


\section{SCHEPANSKI ET AL.: DUST EMISSION FROM ALLUVIAL SOURCES}

Schepanski, K., I. Tegen, and A. Macke (2012a), Comparison of satellite based observations of Saharan dust source areas, Remote Sens. Environ., 123, 90-97, doi:10.1016/J.RSE.2012.03.019.

Schepanski, K., T. J. Wright, and P. Knippertz (2012b), Evidence for flash floods over deserts from loss of coherence in InSAR imagery, J. Geophys. Res., 117, D20101, doi:10.1029/2012JD017580.

Schuster, G. L., M. Vaughan, D. MacDonnell, W. Su, D. Winker, O. Dubovik, T. Lapyonok, and C. Trepte (2012), Comparison of CALIPSO aerosol optical depth retrievals to AERONET measurements, and a climatology for the lidar ratio of dust, Atmos. Chem. Phys., 12, 7431-7452, doi:10.105194/ACP-12-7431-2012.

Shao, Y. (2008), Physics and Modelling of Wind Erosion, 2nd ed., 452 pp., Springer Media, Springer Netherlands.

Shao, Y., K.-H. Wyrwoll, A. Chappell, J. Huang, Z. Lin, G. H. McTainsh, M. Mikami, T. Y. Tanaka, X. Wang, and S. Yoon (2011), Dust cycle: An emerging core theme in Earth system science, Aeolian Res., 2, 181-204, doi:10.1016/J.AEOLIA.2011.01.001.

Seity, Y., P. Brousseau, S. Malardel, G. Hello, P. Benard, F. Bouttier, C. Lac, and V. Masson (2011), The AROME-France convective-scale operational model, Mon. Weather Rev., 139(3), 976-991, doi:10.1175/ 2010MWR3425.1.

Tegen, I., S. P. Harrison, K. Kohfeld, I. C. Prentice, M. Coe, and M. Heimann (2002), Impact of vegetation and preferential source areas on global dust aerosol: Results from a model study, J. Geophys. Res., 107, 4576, doi:10.1029/2001JD000963.
Tegen, I., K. Schepanski, and B. Heinold (2013), Comparing two years of Saharan dust source activation obtained by regional modelling and satellite observations, Atmos. Chem. Phys., 13, 2381-2390, doi:10.5194/ACP-13-2381-2013.

Tulet, P., V. Crassier, F. Cousin, K. Suhre, and R. Rosset (2005), ORILAM, a three-moment lognormal aerosol scheme for mesoscale atmospheric model: Online coupling into the Meso-NH-C model and validation on the Escompte campaign, J. Geophys. Res., 110, D18201, doi:10.1029/2004JD005716.

Tulet, P., M. Mallet, V. Pont, J. Pelon, and A. Boone (2008), The 7-13 March 2006 dust storm over West Africa: Generation, transport and vertical stratification, J. Geophys. Res., 113, D00C08, doi:10.1029/2008JD009871.

Tulet, P., K. Crahan-Kaku, M. Leriche, and B. Aouizerats (2010), Mixing of aerosols into a mesoscale convective system: Generation, filtering and possible feedbacks on ice anvils, Atmos. Res., 96, 302-314, doi:10.1016/J.ATMOSRES.2009.09.011.

Wurzler, S., T. G. Reisin, and Z. Levin (2000), Modification of mineral dust particles by cloud processing and subsequent effects on drop size distribution, J. Geophys. Res., 105, 4501-4512.

Zender, C. S., H. S. Bian, and D. Newman (2003), Mineral Dust Entrainment and Deposition (DEAD) model: Description and 1990s dust climatology, J. Geophys. Res., 108(D14), 4416, doi:10.1029/2002JD002775. 